\title{
Estilos regionales en la Costa Central en el Horizonte Tardío Una aproximación desde el valle del Lurín
}

Styles régionaux de la côte centrale à l'Horizon Récent. Une approche à partir de la vallée de Lurín

Regional styles of the central coast at the Late Horizon. An approach from the lurin valley

\section{Krzysztof Makowski y Milena Vega Centeno A.}

\section{(2) OpenEdition}

Journals

Edición electrónica

URL: http://journals.openedition.org/bifea/5314

DOI: 10.4000/bifea.5314

ISSN: 2076-5827

\section{Editor}

Institut Français d'Études Andines

\section{Edición impresa}

Fecha de publicación: 1 diciembre 2004

Paginación: 681-714

ISSN: 0303-7495

\section{Referencia electrónica}

Krzysztof Makowski y Milena Vega Centeno A., « Estilos regionales en la Costa Central en el Horizonte Tardío

Una aproximación desde el valle del Lurín », Bulletin de l'Institut français d'études andines [En línea], 33

(3) | 2004, Publicado el 08 diciembre 2005, consultado el 01 diciembre 2020. URL : http://

journals.openedition.org/bifea/5314; DOI : https://doi.org/10.4000/bifea.5314

Este documento fue generado automáticamente el 1 diciembre 2020.

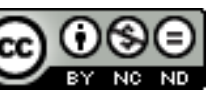

Les contenus du Bulletin de l'Institut français d'études andines sont mis à disposition selon les termes de la licence Creative Commons Attribution - Pas d'Utilisation Commerciale - Pas de Modification 4.0 International. 


\section{Estilos regionales en la Costa Central en el Horizonte Tardío} Una aproximación desde el valle del
Lurín

Styles régionaux de la côte centrale à l'Horizon Récent. Une approche à partir de la vallée de Lurín

Regional styles of the central coast at the Late Horizon. An approach from the

lurin valley

Krzysztof Makowski y Milena Vega Centeno A.

\section{Introducción}

1 Los estudios sobre la cronología de los periodos tardíos en la Costa Central, así como sobre la identidad étnica de los grupos humanos asentados en esta parte del litoral peruano se fundamentaron hasta el presente en algunos supuestos implícitos. El primero de ellos concierne a la supuesta relación directa entre los estilos de la arquitectura pública y de la cerámica, por un lado, y la identidad étnica de las poblaciones. El segundo atañe a la equivalencia entre el grado de centralización del poder político y la uniformidad o variedad estilística perceptibles en la región. Por consiguiente, se espera a menudo que la distribución espacial de ciertos rasgos estilísticos o estilístico-formales (previamente seleccionados con fines cronológicos) dé una definición precisa de las fronteras de señoríos prehispánicos, y confirme o descarte la exactitud de informaciones recogidas por los cronistas y visitadores españoles, o conservadas en documentos judiciales. En los últimos años se multiplicaron justificadas críticas hacia la tradicional equivalencia entre la cultura material y el ethnos, tan fuertemente enraizada en la arqueología antes y después de la influyente polémica de Gordon Childe con Gustaf Kossinna (Graves-Brown et al., 1996; Sillar \& Dean, 2002, inter 
alia). La correspondencia directa entre el espacio político, el estilo cerámico y arquitectónico y la identidad étnica se da en contados casos, y requiere de condiciones especiales para manifestarse, como por ejemplo:

2 1. Cuando la construcción, o la producción y la distribución estén organizadas y normadas centralmente por las instancias del poder dominadas por un solo componente étnico.

3 2. Cuando la identidad étnica, derivada de la conciencia de ser diferente de los vecinos y/o ser amenazado por ellos, se exprese en estilo, tal como efectivamente ocurre a veces con las sociedades fragmentarias (véase las culturas de la selva peruana, por ejemplo Shipibo-Conibo, DeBoer \& Moore, 1982; DeBoer, 1992).

4 En el caso de la costa y de la sierra de los Andes Centrales, la supuesta equivalencia entre el estilo, la organización política y la identidad étnica de elite se nutría y se nutre aún de aparentes argumentos empíricos con las evidencias concernientes a la difusión de formas y diseños inca en cerámica, textiles y arquitectura. Pocos autores supieron escapar a la tentación de agrupar, como pertenecientes a la época anterior a la conquista inca, a todos los alfares, formas, técnicas y diseños decorativos que carecen de claros componentes, cuyo origen podría atribuirse a los artesanos de Cuzco imperial. Para comprobarlo basta revisar los primeros y muy meritorios intentos de construir la cronología regional de la Costa Central en los periodos tardíos por Lavallée (1965-1966: 241). Feltham (1983), Bazán (1990; 1992), Paredes \& Ramos (1994: 347), y recientemente también Eeckhout (1999), Díaz \& Vallejo (2002). Asimismo, solo las variables con indudables paralelos cuzqueños, y en particular los fragmentos de aríbalos polícromos, sirvieron de elementos diagnósticos exclusivos del Horizonte Tardío en los estudios de material de superficie, y también de contextos estratigráficos excavados.

5 Por nuestra parte, tenemos dudas si los supuestos mencionados son aplicables a los periodos tardíos y a las complejas relaciones políticas y socioeconómicas que las caracterizan. Consideramos que el seguimiento de la cronología y de la distribución espacial de estilos de cerámica da cuenta directa de la organización de la producción y distribución de los artefactos ${ }^{(1)}$. Las redes de distribución de recipientes cerámicos de variada función utilitaria y ritual no tienen por que guardar siempre una relación espacial y temporal con las identidades políticas o étnicas de los usuarios. En cambio, los estudios de iconografía y de la historia de diseños decorativos pueden llevar a esclarecer los mecanismos de relaciones entre elites, de los mecanismos del poder y en particular del papel de la ideología religiosa (Earle, 1987; Cook, 1994; Makowski (comp.), 2000-2001; Makowski, 2004).

6 El caso del Horizonte Tardío es particularmente ilustrativo al respecto. El imperio crea condiciones de mini sistema-mundo (Wallerstein, 1973; Wilkinson, 1991; Peregrine, 1991; La Lone, 1994; Chase Dunn \& Hall, 1997; véase también Salomon, 1980; 1986; 1987 y su comparación entre las áreas nor- y centro-andina); los productos y los ejes de distribución interconectan a poblaciones de muy variado origen (Lorandi, 1988; 1991; D'Altroy et al., 1992) y por ende, las identidades de productores, distribuidores, constructores de espacios domésticos y públicos raramente coinciden. Las ideologías imperiales suelen materializarse en arquitectura ceremonial y en la parafernalia de culto oficial, pero no necesariamente impregnan de su particular sello la arquitectura residencial, y la producción de cerámica, textiles e incluso artefactos de metal. Sus productores siguen expresándose en estilos y tecnologías regionales e incluso locales (Morris, 1995; 1998, Lynn Bray, 2003). En todas estas esferas de producción y 
creatividad aflora la identidad del productor o constructor y eventualmente la procedencia del usuario. Los investigadores que trabajan en la Costa Central conocen la situación de la coexistencia de un número importante de estilos de cerámica y de textiles dentro de la misma área e incluso dentro del mismo contexto primario, sea este entierro humano o piso de ocupación (véase también Malpass, 1993; Hayashida, 1994). Esta situación ya ha sido constatada por Uhle (Shimada, 1991; Kaulicke, 1998), Strong \& Corbett (1943: 56) que describen el estilo inca y los estilos asociados al mismo, y por Lavallée (1965-1966: 241). Las excavaciones recientes en los valles del Lurín y del Rímac la han confirmado (Paredes \& Ramos, 1994; Isla, 1995; Franco, 1996; 1998; Eeckhout, 1999; 1998a; b; 2000; Cock \& Goycochea, 2004; Diaz \& Vallejo, 2002; Guerrero, 2004). La revisión de estas evidencias conduce a algunas preguntas.

7 Por un lado, la importancia que se supone que el santuario de Pachacamac tuviera antes de la conquista de la Costa Central por los incas, en el Horizonte Medio y en el Periodo Intermedio Tardío, debería expresarse en una variedad de estilos locales y foráneos. Recordemos que se usaba el paralelo de Pachacamac para interpretar al fenómeno Chavín, y esta comparación se sustentaba entre otros, en numerosos hallazgos de alfarería en los más variados estilos regionales (Burger, 1988; 1993) dentro y alrededor del templo en las orillas de Mosna. En el caso de Pachacamac esta diversidad es un hecho, por lo menos en cuanto al Horizonte Medio 2 y 3 (Shimada, 1991; Dulanto, 2001; Kaulicke, 2001; véase también el caso de Cajamarquilla: Mogrovejo, 1999; Segura, 2001). Por el otro lado, existe un marcado e implícito consenso entre los investigadores que las vasijas en estilo inca se producían localmente (Lavallée, 1965-1966; Feltham, 1983) con un abanico amplio de tecnologías, variantes formales y decoraciones en los que se mantienen vivos varios componentes de las tradiciones de alfarería costeña, no-inca o pre-inca. De ahí se desprende que la producción de la cerámica local no ha sido necesariamente sustituida del todo por las técnicas y diseños imperiales.

8 La reflexión sobre la variabilidad de formas, diseños y técnicas de cerámica de periodos tardíos en la Costa Central es tan antigua como la arqueología científica y se inicia con los estudios de Reiss, Stübel y Uhle. No debe extrañar por ende que la manera de concebir el estilo como fenómeno cultural y como herramienta, y ponderar las variables de análisis, varía sustancialmente entre los autores, de generación en generación, en estrecha relación con los cambiantes modos de entender la cultura, el proceso y las razones de cambio en la prehistoria. Unos autores hacían prevalecer en su definición la relación con las formas y diseños foráneos, o los vínculos comprobables con los antecedentes tecnológicos y morfológicos locales en el Periodo Intermedio Temprano o Horizonte Medio. Otros subordinaban su clasificación a los variables relacionados con el acabado y la decoración, otros más, consideraron prioritario enfatizar los criterios tecnológicos que atañen a la pasta y a las técnicas de construcción (alfares) (2). Como destacarán Conkey \& Hastdorf (1990: 1) citando a Sauerländer (1983: 254): el estilo es "una construcción hermenéutica altamente condicionada y ambivalente que se elabora en distintos momentos de la historia social e intelectual" (3). Consideramos también que el estilo constituye en el mismo tiempo un fenómeno histórico y social, y un herramienta construida por el investigador cuya agudeza y utilidad depende de cómo se la concibe. Por otro lado, a todas las investigaciones realizadas en el transcurso de los últimos 100 años se aplicaría en algún grado la crítica de Davis (1990: 25). A pesar de los aportes de un Panofsky y un Kubler, o un Binford, Wobst o Hodder, en la mayoría de los estudios de historia de arte y arqueología del siglo XX, los análisis estilísticos partían de un supuesto falaz, a saber: 
los diseños, los principios de composición, la variabilidad de rasgos materiales clasificables pueden describirse en abstracción del contexto social, es decir en abstracción de los procesos tecnológicos, y en abstracción de las funciones y de los significados que los productores y los usuarios asignaron a los objetos e imágenes de acuerdo con su morfología y su decoración. Se espera de manera paradójica que esta "pura y a-histórica descripción estilística", la que tampoco controla los prejuicios del investigador, fundamentados por las estéticas y los hábitos de su propia cultura (Davis, 1990), lleve al entendimiento del proceso histórico del pasado y de comportamientos de sociedades no-occidentales y pre-industriales $\left.{ }^{4}\right)$.

9 Compartimos con Davis (1990: 19-21) el convencimiento de que en la práctica de investigación el estilo es equivalente al taxón, siendo fruto de clasificación analítica mediante la cual se crean clases politéticas $\left({ }^{5}\right)$, con criterios en parte subjetivos y relacionados con la metodología del autor, en parte resultantes de la comparación empírica entre el universo investigado (contenido de una unidad estratigráfica, hallazgos en un sitio arqueológico previamente desconocido, etc.) y los paralelos a disposición en la época en la que se realiza el estudio. Los intentos cada vez más decididos, y sofisticados desde el punto de vista teórico, para dar dimensión antropológica al concepto de estilo y anclarlo dentro del contexto más amplio de producción (cadenas operativas: vg. Dietler \& Herbich, 1998; Dobres, 2000), de distribución, de transmisión de la información tecnológica, y del ejercicio del poder (vg. Earle, 1987) no llegan aún a tener impacto en la práctica de investigación sobre la costa central prehispánica. Se requiere de una profunda revisión de conceptos clasificatorios y de un sistemático seguimiento de la distribución de talleres con sus tradiciones tecnológicas previamente definidas (a partir de análisis petrográficos en el caso de cerámica), con el listado de los estilos locales y foráneos que estos talleres son capaces de reproducir o imitar, y con los espacios sociales que abastecen. Ello requiere de un esfuerzo mancomunado de varios proyectos para conformar una base de datos a partir del muestrario común, alimentado con los subsiguientes resultados de análisis petrográficos, siempre y cuando los estudios estén realizados con metodologías compatibles. Esta tarea sobrepasaría por supuesto con creces el marco de esta investigación. Tampoco constituye nuestro objetivo que se limita a dos tareas precisas anunciadas previamente. Queremos demostrar que:

10 1. Los procedimientos tecnológicos de los alfareros, las formas y los diseños previos a la conquista de la Costa Central por los incas no han sido mayormente afectados por la coyunturas políticas y seguían en uso después de la incorporación de estos valles al Tahuantinsuyu.

11 2. La complejidad política del Imperio Inca tiene una directa expresión en la variedad de estilos, la que se desprende tanto de la co-existencia de las tradiciones locales con la producción de objetos que imitaban a los talleres de la capital, como del desplazamiento forzado de alfareros a lo largo del territorio imperial.

12 Más allá de precisiones necesarias en el futuro, resulta ampliamente suficiente usar para este fin las clasificaciones presentes en la literatura del tema de las que se desprende la presencia de variadas tradiciones tecnológicas y estilísticas en los periodos tardíos, en los valles del Lurín y Rimac. Algunas de ellas tienen comprobado su presunto origen local, otras son sin duda de procedencia foránea, otras parecen haberse formado gracias a la asimilación selectiva de algunos procedimientos de acabado e 
imitación de diseños decorativos que se originaron fuera de ambas cuencas. De manera preliminar se vislumbran los siguientes conjuntos:

13 - la cerámica comparable desde el punto de vista formal y de decoración con la producción de talleres cuzqueños, en particular los aríbalos Cuzco Polícromo A; en este grupo las imitaciones locales suelen constituir casi $100 \%$ de la muestra siendo muy poco frecuentes los casos comprobados de importaciones (vg. Inca-Pachacamac de Lavallée, 1965-1966: 241; Inca de Eeckhout (1999); Inca asociado b de Franco, 1998);

14 - la cerámica comparable formalmente y por las características de la pasta con las tradiciones difundidas en la sierra de Lima (Feltham, 1983: 404; Farfán, 1994; Guerrero, 2004: 172, fig. 21, véase también el estilo Cuculi de Engel, 1966);

15 - la cerámica que posee algunos rasgos de decoración, acabado y detalles formales que permiten relacionarla con variados estilos del Horizonte Tardío (vg. Chimú-Inca) y que, además, suele aparecer en asociaciones con estilos cuzqueños (vg. Inca asociado de Strong \& Corbett, 1943: 56, que comprende "negro pulido", "blanco sobre rojo", "negro y blanco sobre rojo" etc.; o el estilo derivado del Inca local en la clasificación de Eeckhout (1999: 30-31);

16 - la cerámica con préstamos estilísticos e imitaciones posiblemente originarios de las áreas de la costa al sur del valle del Lurín y al norte del valle del Chillón (vg. el estilo Puerto Viejo, Bonavía, 1959);

17 - la cerámica que carece de características o préstamos foráneos, salvo los que proceden de los vecinos de la Costa Central, y que suele encontrarse en contextos posteriores al Horizonte Medio 3. Se propone para ella la denominación Ychsma o Ichma (vg. Bueno, 1982: 41-42; Bazán, 1990; Shimada, 1991: XXVII; Isla, 1995: 87).

18 Los últimos dos grupos son los más problemáticos por dos razones. La principal fuente de potenciales confusiones se desprende de la escasez de contextos primarios excavados y publicados hasta el presente que cuenten con estratigrafía firme, y abundante material diagnóstico. Solo el comienzo de la secuencia relacionada con el Horizonte Medio 3-4 está sólidamente respaldado, entre otros por los contextos funerarios de Ancón, y más recientemente, por los de Huallamarca y Armatambo (Guerrero, 2004). Por esta razón las definiciones de la cerámica Ychsma o Ichma varían drásticamente entre los autores, de acuerdo con la idea que cada uno de los investigadores tiene sobre la evolución estilística y el peso de préstamos foráneos durante el Periodo Intermedio Tardío y Horizonte Tardío. Hace 20 años Bueno (1982: 41-42) escribió:

19 "el estilo Ichma se caracteriza por... cuencos, cántaros y ollas que frecuentemente presentan decoración estampada y pintura blanco sobre rojo. También se caracteriza por la presencia de cántaros modelados que presentan figuras humanas y animales de cierto parecido a los de Chancay Tardío".

20 En las publicaciones recientes de Díaz \& Vallejo (2002) y Guerrero (2004) la tradición cerámica local comprende formas mayormente utilitarias de cántaros y ollas con poca decoración y baja calidad en cuanto a la cocción y acabado.

21 Afortunadamente en la última década se realizaron varias excavaciones sistemáticas, y en área, en asentamientos y cementerios con la ocupación del Horizonte Tardío bien fundamentada, gracias a la estratigrafía y a las firmes asociaciones con la cerámica diagnóstica Inca: los cementerios de Rinconada de Lago y Huaquerones (Guerrero, 2004; Cock \& Goycochea, 2004) en el valle del Rímac y el asentamiento de Pueblo Viejo-Pucara 
en el valle del Lurín. Consideramos que el análisis de la relación entre las tecnologías y diseños locales y foráneos en el material cerámico del Horizonte Tardío es el primer paso, y quizás el más importante, para poder luego definir el o los estilos locales producidos por los ceramistas en las cuencas bajas del Rímac y Lurín en el hipotético territorio del señorío Ychsma (Rostworowski, 1972; 1978).

\section{Pueblo Viejo-Pucará}

Este asentamiento urbano del Periodo Horizonte Tardío (aprox. 1470 - 1533 d.c.) se encuentra ubicado (Fig. 1) en el laberíntico sistema de quebradas laterales que atraviezan las primeras estribaciones de los Andes en la margen izquierda del río Lurín ${ }^{(6)}$. Las dos fases definidas estratigraficamente en todos los sectores excavados corresponden al Horizonte Tardío, un terremoto que causa el colapso de parte de las estructuras marca el fin de la primera fase (Fig. 2). Hasta el presente, todas las evidencias registradas apuntan hacia el abandono del asentamiento poco después de la llegada de los españoles puesto que no se cuenta con ningún material colonial, salvo dos cuentas de vidrio en la capa de abandono en el sector II, probable residencia del curaca y de su linaje. Con sus 10 ha de área construida, sin contar el sistema de andenería ni los sitios satélites, Pueblo Viejo-Pucará parece haber sido el segundo asentamiento en importancia después de Pachacamac, luego de la ocupación de este valle por los incas. Es probable que se trate del asentamiento principal de los Caringa de Huarochirí, una de las dos parcialidades de la mitad Caringa en el unu de Luren (Makowski, 2003: 165). La característica distribución de núcleos de arquitectura en las cimas intermedias y la localización del sitio en la zona de pasturas utilizada hasta hoy por los pastores serranos de Santo Domingo de los Olleros, la manpostería de piedra en las modalidades desconocidas en la Costa Central, pero difundidas en las alturas de Huarochirí, la organización modular de espacios domésticos, los comportamientos funerarios y la presencia del componente serrano en el repertorio de estilos de cerámica, indican que el asentamiento fue construido y habitado por los pobladores serranos desplazados por iniciativa política de los gobernantes del Tahuantinsuyu. 
Fig. 1 - Ubicación de Pueblo Viejo-Pucará en el valle del Lurín

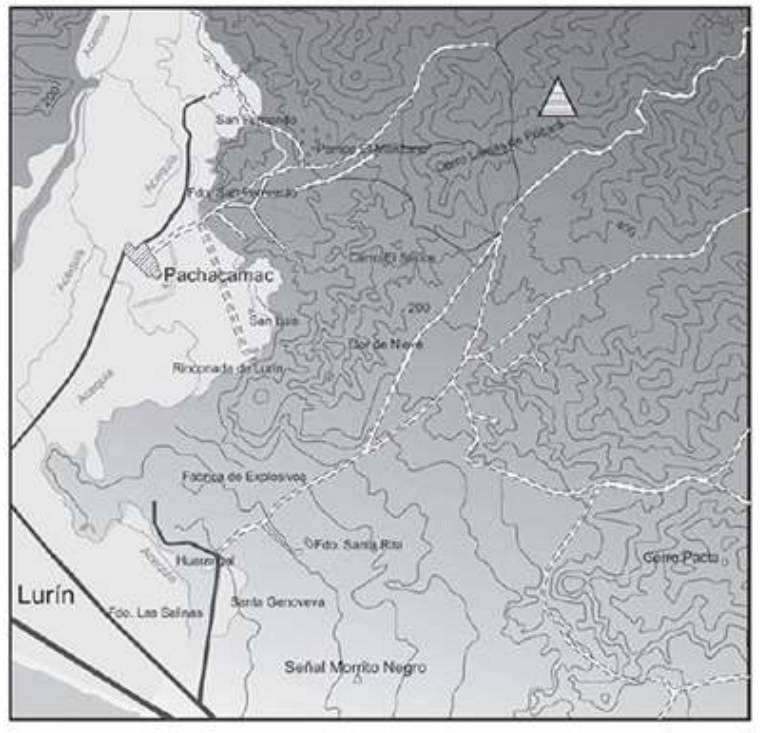

$\triangle$ Pueblo Viejo

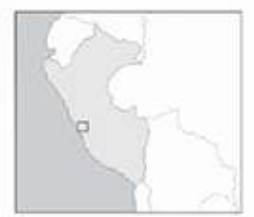

Fig. 2 - a. Estratigrafía típica en el interior de las estructuras domésticas: estructura EA11, Sector III, perfil Sur. b. cerámica diagnóstica Inca de diferentes contextos domésticos
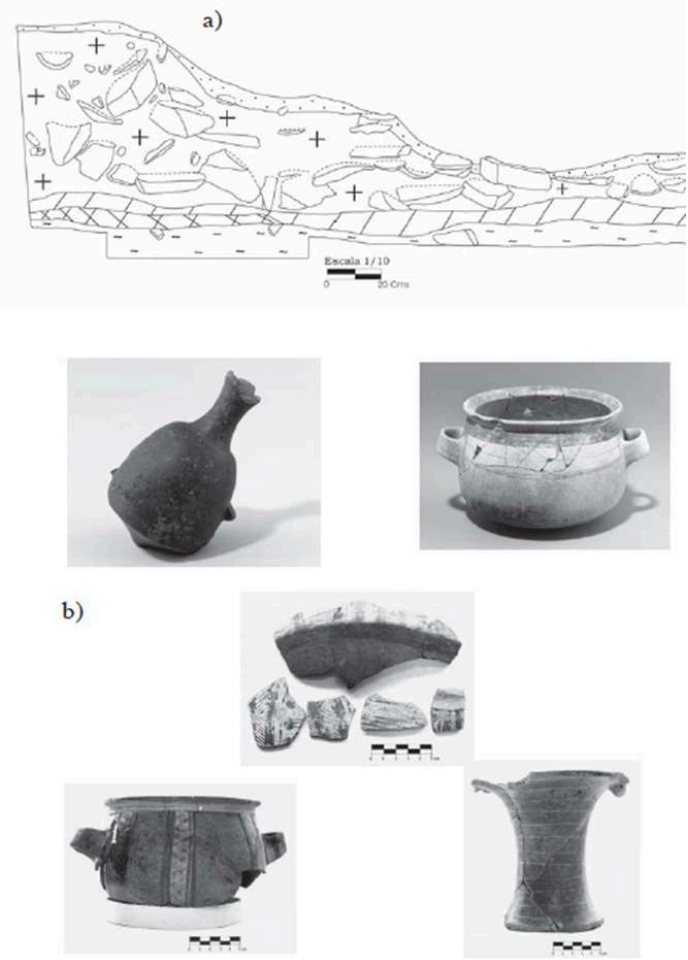

DIBUJO CRISTINA ROSPIgLIOSI 

distribuidas entre cuatro aglomeraciones de arquitectura doméstica distantes unos de otros 200-300 m en promedio, además de dos complejas estructuras de diseño ortogonal con patios internos y amplios espacios de almacenamiento. Estas últimas poseen características de residencia de elite. Hay también dos pequeños sitios-satelite en los caminos de acceso desde la sierra que atraviezan las vecinas quebradas de Pucaráo y de Río Seco. Dos aglomeraciones y una de las dos residencias de elite se encuentran distribuidas en las cimas desde las cuales se domina visualmente la costa con la entrada al valle, y el acceso al santuario de Pachacamac desde el sur. Las dos aglomeraciones restantes y la más monumental de las dos residencias "palaciegas" están escondidas en el fondo de las quebradas tributarias de la quebrada Pueblo Viejo, al abrigo de los dos lugares fuertes (pucaras) arriba mencionados, siendo protegida adicionalmente por la muralla natural conformada por terrazas fósiles, cuya forma recuerda la de las morenas laterales del paisaje glacial. La ubicación es estratégica tanto desde el punto de vista ofensivo como defensivo.

\section{Procedencia de la muestra}

En este trabajo hemos tomado en cuenta una muestra representativa del abundante material cerámico procedente del Sector III (una de las cuatro aglomeraciones de arquitectura residencial). Como las otras, esta aglomeración se compone de un conjunto de unidades plaza integradas por 3 a 5 casas, cuyas entradas dan al patio común. En este sector se ha excavado $1080 \mathrm{~m}^{2}$ en área, tanto de la arquitectura doméstica como dos áreas de descarte de basura; una de estas áreas tiene el carácter de un gran basural estratificado (Figs. 3, 4). Por estas razones la muestra de este sector es particularmente representativa para ambas fases de ocupación del asentamiento durante el Horizonte Tardío. Sin embargo, no excluimos que hay diferencias en las proporciones de alfares entre los sectores, las residencias comunes y los dos conjuntos arquitectónicos de elite que destacan por sus amplias dimensiones, trazo ortogonal y amplios patios o plazas cercadas (respectivamente los sectores II y IV-1) $\left(^{(7)}\right.$.

Bulletin de l'Institut français d'études andines, 33 (3) | 2004 
Fig. 3 - Pueblo Viejo-Pucará, Sector III: a. Plano de aglomeraciones de arquitectura doméstica con unidades patio reconocidas y la ubicación del extenso basural estratigraficado (unidad 4)

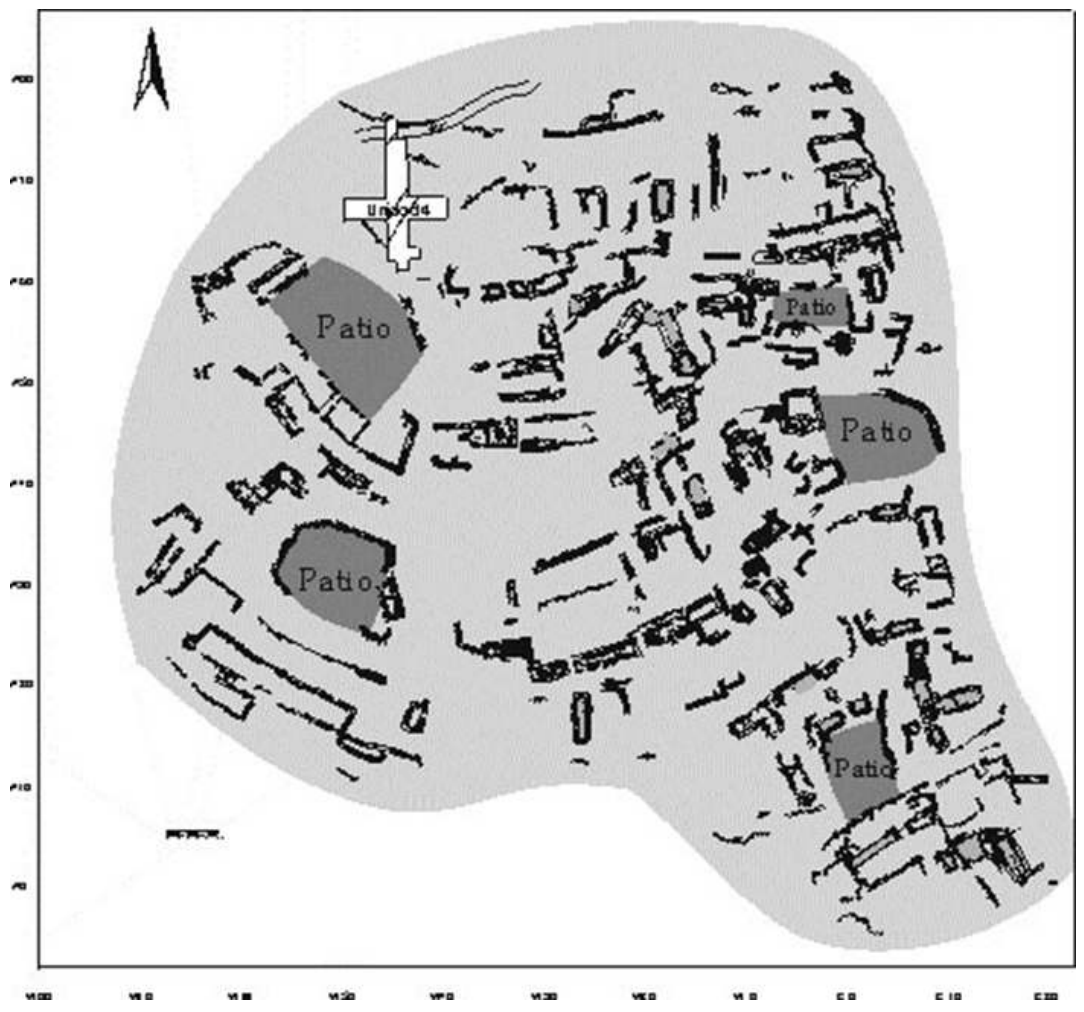

Fig. 3 - Pueblo Viejo-Pucará, Sector III: b. vista del sector desde el oeste

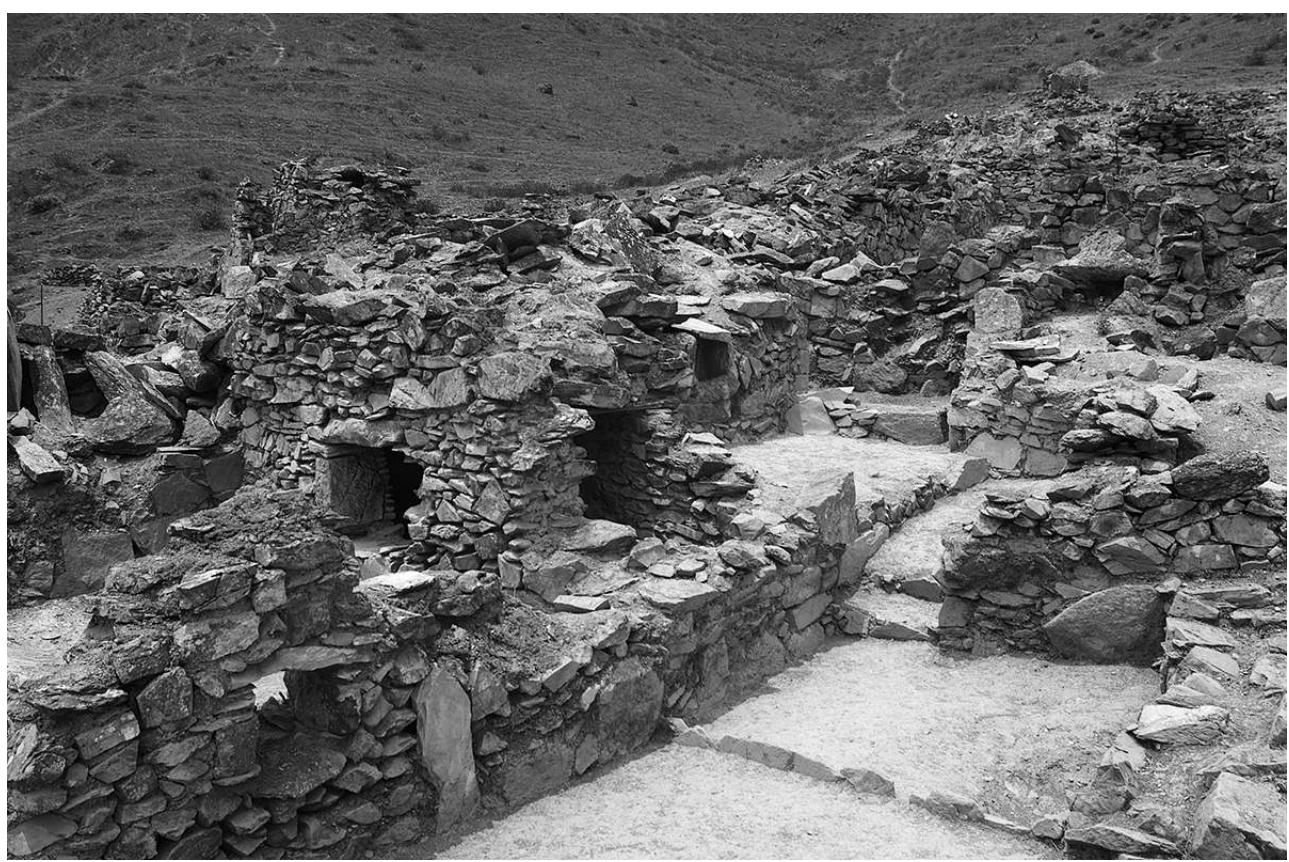


Fig. 4 - Basural en la unidad 4, Sector III, corte estratigráfico Este-Oeste

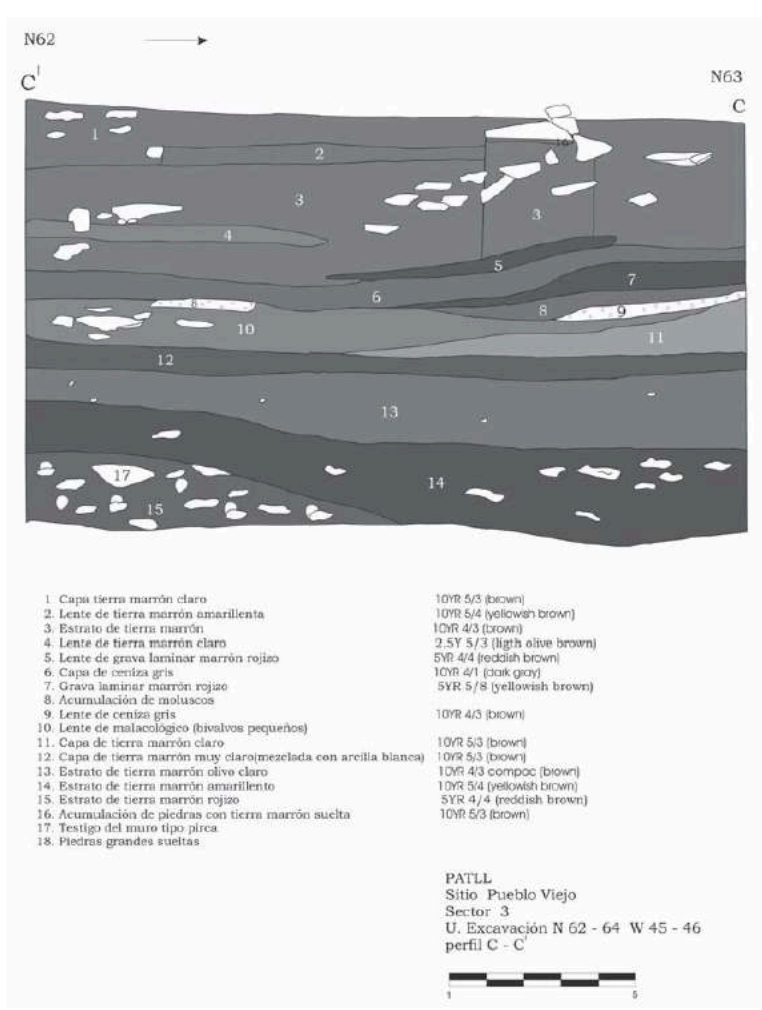

DibUjo MILENA VEga CENTENO

\section{Resultados de los análisis ceramológicos}

Gracias al cruce de información procedente de las excavaciones de zonas de actividad, zonas de residencia y zonas de descarte se ha podido concluir que, según toda probabilidad, los pobladores de Pueblo Viejo no producían localmente ningún tipo de cerámica, salvo un caso aislado de confección de figurinas de molde. Ello se desprende, en primera instancia de la ausencia de piezas mal cocidas, deformadas o bizcochos (Vega Centeno, 2004: 185). Tampoco hemos encontrado hornos o lugares de confección y acabado o eventuales instrumentos como pulidores, platos de alfarero, paletas, etc. La forma de plato de alfarero está presente en un alfar serrano, pero en número limitado de casos. Hay también varias evidencias indirectas a favor de esta conclusión. Son muy frecuentes los casos de reuso de fragmentos de cerámica para hacer figurinas, raspadores y piruros. Por otro lado, en sitios donde se producía localmente la cerámica, los hallazgos de ollas y cántaros reparados suelen ser excepcionales, en cambio, en Pueblo Viejo-Pucará tenemos varios ejemplos de fragmentos con filas de perforaciones de ambos lados de una grieta, para poder consolidar el recipiente y seguir usándolo (Vega-Centeno, 2004: 185). Finalmente, la gran diversidad de pastas (Cuadro 1), tipos morfológicos, y estilos con diseños y técnicas de decoración particulares, demuestran que los habitantes del asentamiento tuvieron acceso a la producción procedente de varios talleres ubicados en la costa y en la sierra central. 
Cuadro 1 - Los alfares de Pueblo Viejo y sus principales características $\left(^{8}\right)$

\begin{tabular}{|c|c|c|c|c|}
\hline $\begin{array}{l}\text { Pasta } \\
\text { Alfar }\end{array}$ & & Características & Diseños & Diseños \\
\hline Alfar & A & $\begin{array}{l}\text { - Pintura precocción: negro- } \\
\text { crema sobre rojo, crema sobre } \\
\text { engobe, rojo y negro sobre } \\
\text { crema }\end{array}$ & $\begin{array}{l}\text { Antropomorfos, aves, } \\
\text { serpientes aplicadas, peces } \\
\text { y mayormente geométricos }\end{array}$ & $\begin{array}{l}\text { Cántaros, cantaros } \\
\text { cara-gollete, ollas, } \\
\text { figurinas y aríbalos }\end{array}$ \\
\hline & & - modelados y acoplados & Choclos de maíz & Cántaros \\
\hline Alfar & B & $\begin{array}{l}\text { - Pintura precocción: negro- } \\
\text { blanco sobre engobe rojo, } \\
\text { crema sobre engobe rojo y } \\
\text { negro sobre crema }\end{array}$ & $\begin{array}{l}\text { Geométricos } \\
\text { antropomorfos }\end{array}$ & $\begin{array}{l}\text { Cántaros cara- } \\
\text { gollete, cántaros, ollas } \\
\text { y figurinas }\end{array}$ \\
\hline $\begin{array}{l}\text { Alfar } \\
3\end{array}$ & C & $\begin{array}{l}\text { - Pintura precocción: franjas } \\
\text { negras sobre engobe rojo }\end{array}$ & Geométricos & $\begin{array}{l}\text { Cántaros muy } \\
\text { grandes ("tinajas") }\end{array}$ \\
\hline $\begin{array}{l}\text { Alfar } \\
4\end{array}$ & $\left|\begin{array}{ll}\text { D } & \text { y } \\
\text { H } & \end{array}\right|$ & $\begin{array}{l}\text { - Apliques y pintura post- } \\
\text { cocción en las incisiones }\end{array}$ & Incisiones geométricas & $\begin{array}{l}\text { Cántaros, botellas } \\
\text { miniatura, cuencos y } \\
\text { olla miniatura inca }\end{array}$ \\
\hline $\begin{array}{l}\text { Alfar } \\
5\end{array}$ & \begin{tabular}{|l|}
$E-1$ \\
E-2 y \\
$F$
\end{tabular} & $\begin{array}{l}\text { - Marrón llano } \\
\text { - Apliques }\end{array}$ & $\begin{array}{l}\text { Pintura roja post-cocción } \\
\text { Serpientes aplicadas }\end{array}$ & $\begin{array}{lr}\text { Cántaros, } & \text { ollas, } \\
\text { platos, } & \text { cuencos } \mathrm{y} \\
\text { algunos } & \text { platos } \\
\text { alfareros } & \end{array}$ \\
\hline $\begin{array}{l}\text { Alfar } \\
6\end{array}$ & $\begin{array}{l}\mathrm{G} 1 \mathrm{y} \\
2\end{array}$ & $\begin{array}{l}\text { - Pintura precocción: franjas } \\
\text { cremas sobre pasta, crema } \\
\text { sobre engobe rojo y negro } \\
\text { sobre marrón }\end{array}$ & $\begin{array}{l}\text { Antropomorfos y } \\
\text { mayormente geométricos }\end{array}$ & $\begin{array}{ll}\text { Cántaros, ollas } \mathrm{y} \\
\text { cuencos miniatura } \mathrm{y} \\
\underline{\text { aríbalos }}\end{array}$ \\
\hline & & Estampado & Diseños geométricos & Ollas \\
\hline & & - Apliques & De tipo "ojos de papa" & ¿Ollas o cántaros? \\
\hline $\begin{array}{l}\text { Alfar } \\
7\end{array}$ & I & Incisiones y superficie & Líneas paralelas & $\begin{array}{l}\text { Cuencos miniature y } \\
\text { botellas }\end{array}$ \\
\hline $\begin{array}{l}\text { Alfar } \\
8\end{array}$ & $\mathrm{~J}$ & $\begin{array}{l}\text { Pintura precocción: negro } \\
\text { sobre crema, negro-crema } \\
\text { sobre rojo y crema sobre } \\
\text { engobe rojo }\end{array}$ & $\begin{array}{l}\text { Antropomorfos } \\
\text { geométricos }\end{array}$ & $\begin{array}{l}\text { Cántaros cara- } \\
\text { gollete. Ollas y } \\
\text { cuencos y aríbalos }\end{array}$ \\
\hline $\begin{array}{l}\text { Alfar } \\
9\end{array}$ & K & $\begin{array}{l}\text { - Pintura precocción: negro- } \\
\text { crema sobre rojo, negro sobre } \\
\text { engobe rojo, crema sobre } \\
\text { engobe rojo y negro sobre } \\
\text { crema }\end{array}$ & $\begin{array}{l}\text { Antropomorfos } \\
\text { geométricos }\end{array}$ & $\begin{array}{l}\text { Cántaros cara- } \\
\text { gollete, cántaro "ojos } \\
\text { llorosos", cántaros, } \\
\text { ollas, cuencos y } \\
\text { aríbalos }\end{array}$ \\
\hline
\end{tabular}




\begin{tabular}{|c|c|c|c|c|}
\hline $\begin{array}{l}\text { Alfar } \\
10\end{array}$ & $\mathrm{~L}$ & $\begin{array}{l}\text { - Pintura precocción: franjas } \\
\text { cremas y chorreadas }\end{array}$ & $\begin{array}{l}\text { Mayormente diseños } \\
\text { geomé tricos y escasas } \\
\text { serpientes aplicada }\end{array}$ & $\begin{array}{l}\text { Cántaros, ollas } \mathrm{y} \\
\text { cuencos }\end{array}$ \\
\hline & & - Impresos & Círculos impresos & Cántaros \\
\hline $\begin{array}{l}\text { Alfar } \\
11\end{array}$ & M & $\begin{array}{l}\text { - Pulido, bruñidos y a veces con } \\
\text { apliques }\end{array}$ & Zoomorfos & $\begin{array}{l}\text { Piruros y cuencos } \\
\text { miniatura }\end{array}$ \\
\hline $\begin{array}{l}\text { Alfar } \\
12\end{array}$ & $\mathrm{~N}$ & - Superficie bruñida & & Cuencos y aríbalos \\
\hline $\begin{array}{l}\text { Alfar } \\
13\end{array}$ & 0 & - Superficie bruñida & & $\begin{array}{l}\text { Botellas y cuencos } \\
\text { miniatura }\end{array}$ \\
\hline $\begin{array}{l}\text { Alfar } \\
14\end{array}$ & $P$ & $\begin{array}{l}\text { - Pintura precocción: negro } \\
\text { sobre crema, negro-blanco } \\
\text { sobre engobe rojo y pintura en } \\
\text { incisiones y apliques }\end{array}$ & $\begin{array}{l}\begin{array}{l}\text { Geométricos y escasas } \\
\text { serpientes }\end{array} \\
\underline{ }\end{array}$ & $\begin{array}{l}\text { Cántaros, } \\
\text { ollas y cuencos, } \\
\text { aplicadas }\end{array}$ \\
\hline $\begin{array}{l}\text { Alfar } \\
15\end{array}$ & Q & - ¿Ausente? & & $\begin{array}{l}\text { Cántaros y ollas } \\
\text { pequeñas }\end{array}$ \\
\hline $\begin{array}{l}\text { Alfar } \\
16\end{array}$ & $\mathrm{R}$ & Pintura precocción & Franjas cremas & Cántaros \\
\hline
\end{tabular}

\section{FUENTE: VEgA CENTENO, 2004: 129 CUADRO ${ }^{\circ} 14$}

El análisis convencional macroscópico y microscópico de pastas de la muestra compuesta por 3456 fragmentos diagnósticos seleccionados entre 41871 fragmentos recuperados ha permitido definir 16 alfares y 18 tipos y variantes de pastas. Algunos de los alfares con mayor recurrencia se presentan en más de una variante de la pasta, con ciertas diferencias en cocción, tamaño y densidad de desgrasantes, como el alfar 4 (pastas D y H), alfar 5 (pastas E-1, E-2 y F) y alfar 6 (pastas G-1 y G-2). A pesar de estas diferencias que sugieren variaciones en cuanto a tratamiento de la arcilla y ligeras diferencias en el procedimiento de amasado, el repertorio de formas es casi igual en todos estos casos.

\section{Descripción de pastas}

Pasta A: semi-porosa de textura granular, la fractura regular en ocasiones lisa; las inclusiones muy finas (menores de 0,05 mm), distribuidas de manera homogénea constituyen un $10 \%$ de la pasta; la cocción oxidante, color naranja por lo general (Munsell 5YR 4/6 ó 2,5R 4/8); las inclusiones de mayor recurrencia son las siguientes:

29 - granos sub-angulares y sub-redondeados de cuarzo lechoso de color blanquecino opaco en un $90 \%$ aproximadamente;

30 - partículas no identificadas angulares y a menudo alargadas de roca negra, con la presencia de $9 \%$;

31 - mica dorada o feldespato. 

(Munsell 5YR 6/4 ó 5YR 6/6); las inclusiones muy finas (menos de 0,05 mm), distribuidas de manera homogénea constituyen un aproximado de $10 \%$ de la pasta y comprenden: (0,5-7 $\mathrm{mm})$, por lo general fino a medio, distribuidas de manera homogénea constituyen hasta $50 \%$ de la pasta y comprenden:

YR 4/6); las inclusiones de tamaño fino a medianamente fino, de 0,05 a $1,00 \mathrm{~mm}$ constituyen un $20 \%$ de la pasta y están distribuidas de manera irregular; entre las inclusiones se distinguen:

45 - cuarzo lechoso sub-redondeado y sub-angular con aprox. $79 \%$;

46 - gravilla angulosa y sub-redondeada de color negro oscuro en un $20 \%$;

47 - mica amarilla y feldespato en cantidades que no sobrepasan $1 \%$.

48 Pasta E-2: a diferencia de la anterior tiene la consistencia porosa y la fractura irregular; la textura es granular; su color es también marrón (Munsell 5 YR 5/4). Las inclusiones distribuidas de manera irregular conforman el $30 \%$ de la pasta; destacan entre ellas:

49 - granos gruesos (de aproximadamente $2 \mathrm{~mm}$ ) de cuarzo lechoso de forma subredondeada y sub-angular;

50 - partículas negras angulosas y sub-redondeadas en un porcentaje menor que oscila alrededor del $20 \%$;

51 - cantidades mínimas de mica amarilla y feldespato.

52 Pasta F: semi-porosa de textura laminar, fractura regular, en ocasiones lisa, de color marrón (Munsell 5 YR 5/4). Las inclusiones muy finas (menos de $0,5 \mathrm{~mm}$ ), que constituyen un $5 \%$ de la pasta, están distribuidas de forma irregular y comprenden:

53 - granos de cuarzo lechoso;

54 - en menor porcentaje partículas negras alargadas y angulares de color negro opaco; 

2,5 Y 6/4 ó 2,5 Y 6/6). Las inclusiones muy finas (menos de 0,5 mm), que constituyen solo un $5 \%$ de la pasta, están distribuidas de manera irregular y comprenden:

73 crema, posiblemente arcilla blanca, caolinita o carbonato de calcio;

74 - granos de cuarzo lechoso;

75 - partículas planas de color negro opaco. (Munsell 10 YR 5/6, 10 R 4/8). Las inclusiones de tamaño muy fino (menos de $0,5 \mathrm{~mm}$ ), que constituyen solo un $5 \%$ de la pasta, están distribuidas de manera irregular y comprenden:

77 - granos de cuarzo lechoso de forma sub-angular y sub-redondeada;

78 - partículas negras opacas, de forma plana y angular;

79 - aglomeraciones amorfas de sustancia blanca incrustada en poros, de color blanco a crema, posiblemente arcilla blanca, caolinita o carbonato de calcio; 
80 - granos medianos de color beige, sub-redondeados y angulares.

81 Pasta L: porosa de textura laminar y fractura irregular. Su color es anaranjado claro (Munsell 5 YR 5/8). Las inclusiones de tamaño fino (0,5-1,0 mm) constituyen un $10 \%$ de la pasta y comprenden:

82 - granos de cuarzo lechoso;

83 - diminutas partículas negras angulosas y sub-redondeadas;

84 - granos rosados sub-redondeados y angulares;

85 - mica amarilla o feldespato en mínimas proporciones.

86 Pasta M: compacta, de textura granular y fractura regular, en ocasiones lisa, de color marrón (Munsell 7,5 YR 5/6, 7,5 YR 5/4). Las inclusiones de tamaño muy fino (menos de $0,5 \mathrm{~mm}$ ) constituyen solo un $2 \%$ de la pasta, están distribuidos de manera irregular y comprenden:

87 - granos de cuarzo lechoso;

88 - partículas opacas de color negro, angulares y planos, semejantes al carbón vegetal.

89 Pasta N: semi-compacta, de textura granular y fractura regular, de color rojo claro (Munsell 5 YR 5/8, 5 YR 6/8). Las inclusiones muy finas (menos de 0,5 mm) constituyen tan solo un $3 \%$ de la pasta, están distribuidas de manera homogénea y comprenden:

90 - aproximadamente $60 \%$ de cuarzo lechoso;

91 - un 10 \% de partículas negras, opacas, de formas angulares y alargadas que se asemejan al carbón vegetal;

92 - partículas de mineral negro, angulares, a veces alargadas;

93 - mica amarillenta o feldespato en mínimas cantidades.

94 Pasta 0: semi-porosa, de textura laminar y fractura regular, a veces lisa, de color marrón claro (Munsell 10 YR 6/4). Las inclusiones muy finas (menos de 0,5 mm) constituyen solo un $5 \%$ de la pasta, están distribuidas de manera homogénea y comprenden:

95 - partículas negras opacas, de forma angular alargada, en mayor proporción;

96 - granos brillantes de color blanco o rojizo, de forma sub-redondeada;

97 - granos de cuarzo lechoso.

98 Pasta P: porosa, de textura granular y fractura irregular, de color rojo claro (Munsell 5 YR 5/8). Las inclusiones de tamaño muy fino (menos de 0,5 mm) constituyen un $20 \%$ de la pasta, están distribuidas de manera irregular y comprenden:

99 - granos de cuarzo lechoso;

100 - granos de mineral de color beige, tamaño mediano y de formas sub-redondeadas;

101 - partículas negras brillantes, angulosas y sub-redondeadas.

102 Pasta Q: porosa, de textura granular y fractura irregular, sinuosa, de color rojo (Munsell 2,5 Y 5/8). Las inclusiones de tamaña grueso (entre 1 y $5 \mathrm{~mm}$ ) constituyen un $30 \%$ de la pasta, están distribuidas de manera homogénea y comprenden:

103 - granos angulares y sub-redondeados de cuarzo lechoso;

104 - escasa mica amarilla o feldespato. 
Pasta R: porosa, de textura granular y fractura irregular, de color rojo amarillento o marrón fuerte (Munsell 5 YR 5/6, 7,5 YR 5/6). Las inclusiones de tamaño grueso (de 1 a $5 \mathrm{~mm}$ ), constituyen un $30 \%$ de la pasta, se encuentran distribuidas de manera irregular y comprenden:

106 - granos de cuarzo lechoso;

107 - granos de mineral negro de forma sub-redondeada, en la misma proporción que cuarzo;

108 - granos sub-angulares o sub-redondeados de color rojizo opaco, en un $10 \%$;

109 - granos de roca de color gris opaco, de forma angular y tamaño entre 3 y $5 \mathrm{~mm}$;

110 - mica amarilla o feldespato en cantidades mínimas.

111 Dos son los alfares más recurrentes (Cuadro 2), entre ellos el alfar 5 que parece corresponder a la tradición tecnológica serrana, a juzgar por el repertorio de formas muy características (cántaros con labios reforzados interna y externamente, cántaros con cuellos compuestos, ollas, pequeñas botellas, platos, etc.) y el acabado marrón llano. La única decoración registrada consiste en el uso de pintura roja post-cocción y, en algunos casos, en las serpientes aplicadas (Fig. 5).

Cuadro 2 - Frecuencia de los alfares en Pueblo Viejo

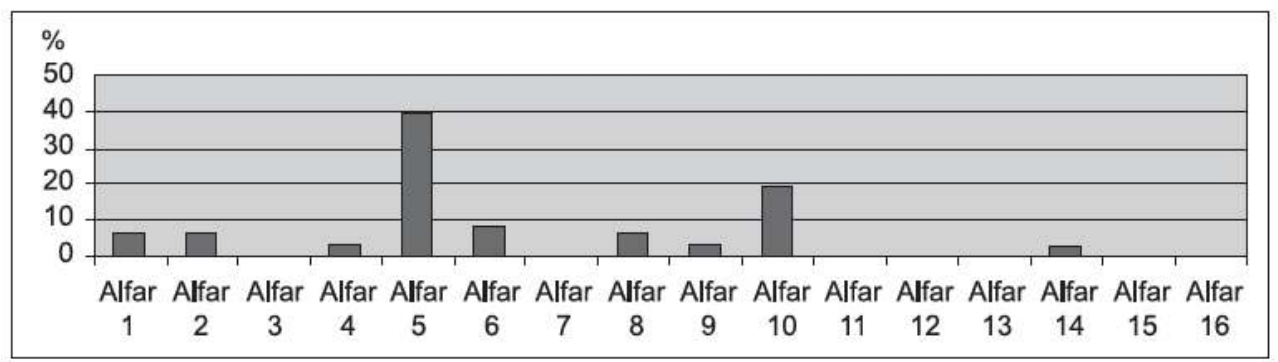

Fig. 5 - Cerámica en estilo serrano, alfar $n^{\circ} 5$
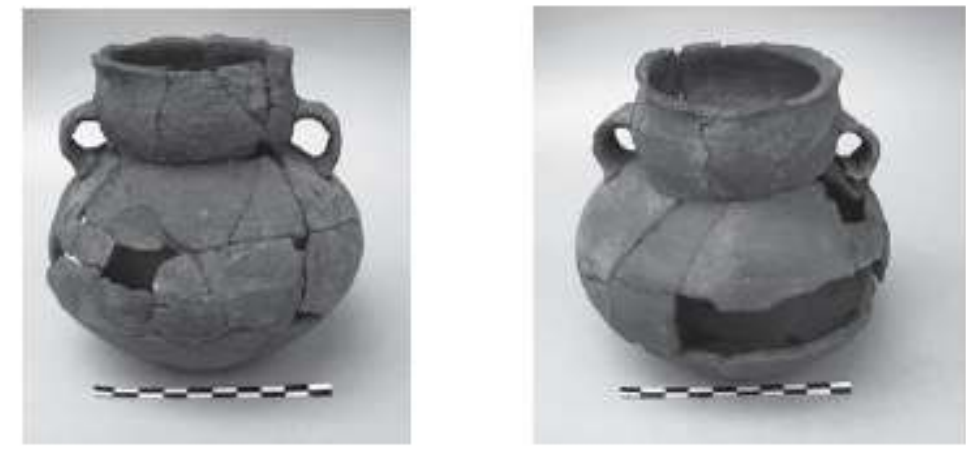

112 El segundo lugar en cuanto a la popularidad (Cuadro 2) ocupa el alfar 10 que se caracteriza por un solo tipo de pasta (L) de color naranja. Las vasijas de este alfar tienen acabado alisado tosco, con decoración de pintura crema chorreada o de franjas verticales en el cuerpo y cuello de las vasijas o al alrededor de las asas (Fig. 6). Las formas registradas corresponden en mayor parte a las que Díaz \& Vallejo (2002) registran en Armatambo y denominan estilo Ychsma Medio $\left({ }^{9}\right)$. La influencia Inca se expresa en la presencia eventual de serpientes aplicadas en el cuello y cuerpo de las 
vasijas. Asimismo, se ha registrado la decoración con círculos estampados, semejantes a los que caracterizan al estilo Lauri impreso (Krzanowski, 1991).

Fig. 6 - Cerámica en estilo Ychsma, alfar $\mathrm{n}^{\circ} 10$
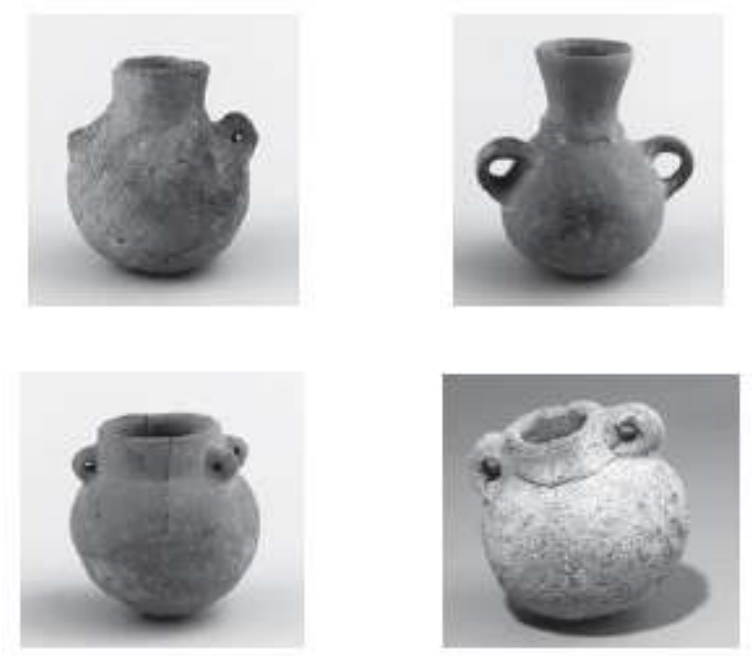

113 No menos recurrente en la muestra de Pueblo Viejo es la tradición alfarera costeña que Bonavia (1959) denominó como Puerto Viejo (Fig. 7). Sin embargo, la fragmentería correspondiente a este estilo se reparte en cuatro alfares, cada uno caracterizado por tipo diferente de pasta: A, B, J y K que corresponde a los alfares $n^{\circ} 1,2$ y 8, 9 (ver cuadro 1). Este estilo local tardío, entre sus características estilísticas y morfológicas más representativas presenta las vasijas cara-gollete con pintura negra-blanca sobre engobe rojo. Bonavia creía que se trataba de un estilo local costeño pre-inca (1959: 116). Sin embargo, hay vasijas que tienen rasgos relacionados con el Horizonte Tardío. Las vasijas Puerto Viejo fueron halladas no solo en el sitio epónimo sur de Chilca, sino también en Pachacamac, en la Isla San Lorenzo (Isla, 1995: 88), Mala (Engel, 1966: 2) y en el valle del Rímac. 
Fig. 7 - Fragmentos en estilo Pueblo Viejo: a. alfar $n^{\circ} 1$

a)
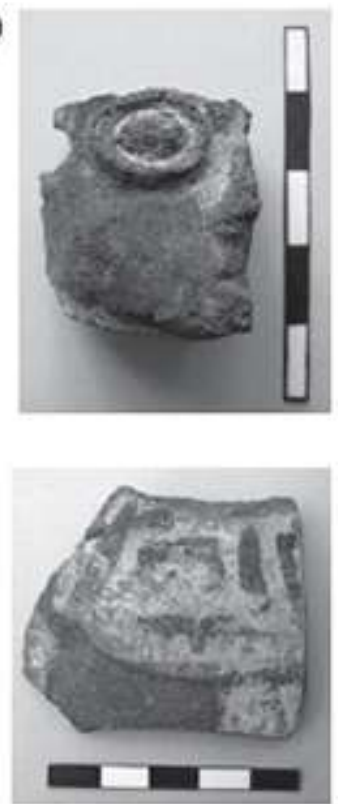
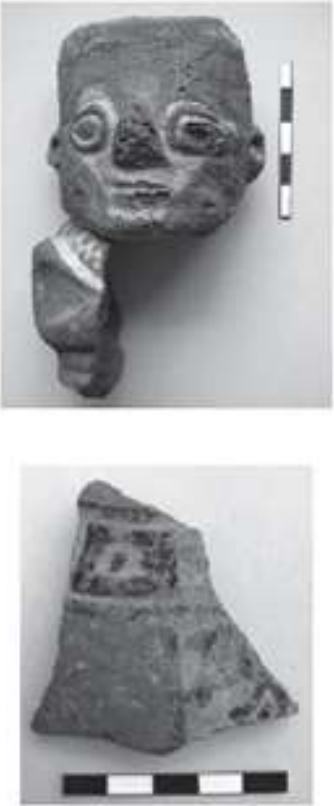
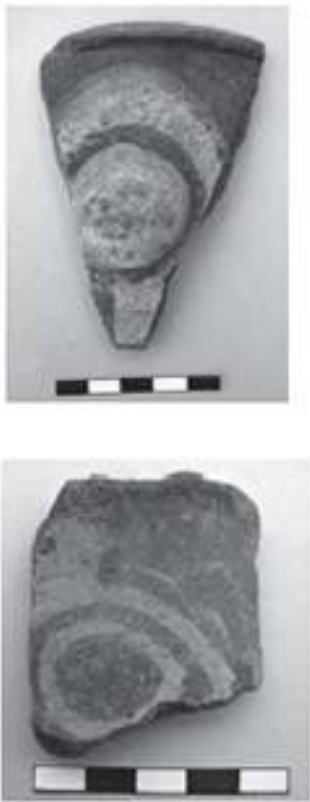

Fig. 7 - Fragmentos en estilo Pueblo Viejo: b. alfar $n^{\circ} 2$

b)
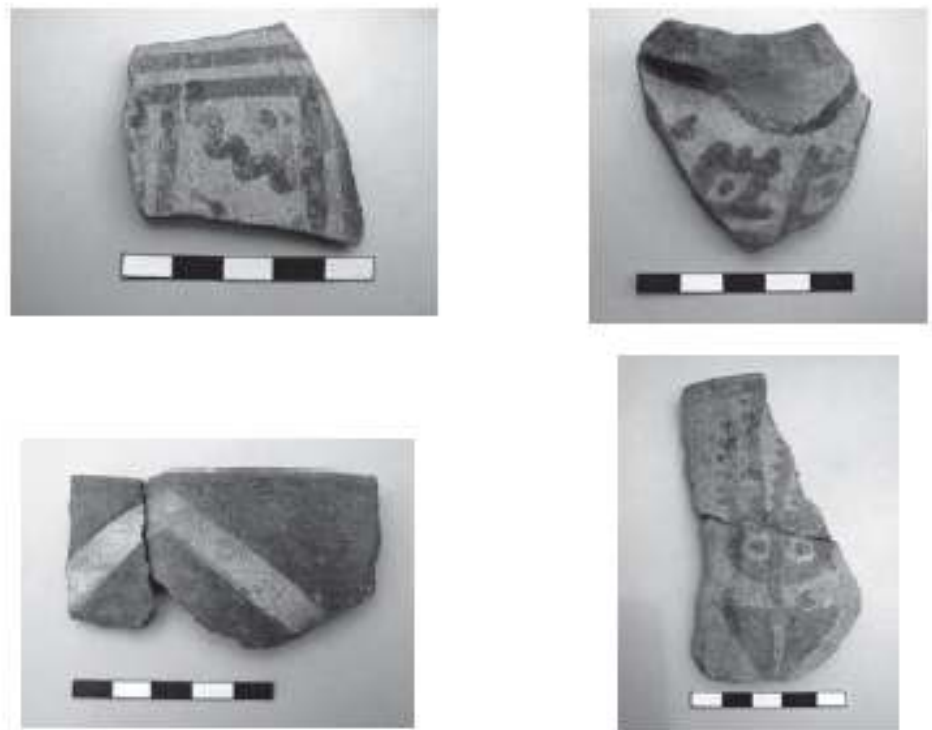
Fig. 7 - Fragmentos en estilo Pueblo Viejo: c. alfar $n^{\circ} 8$

c)
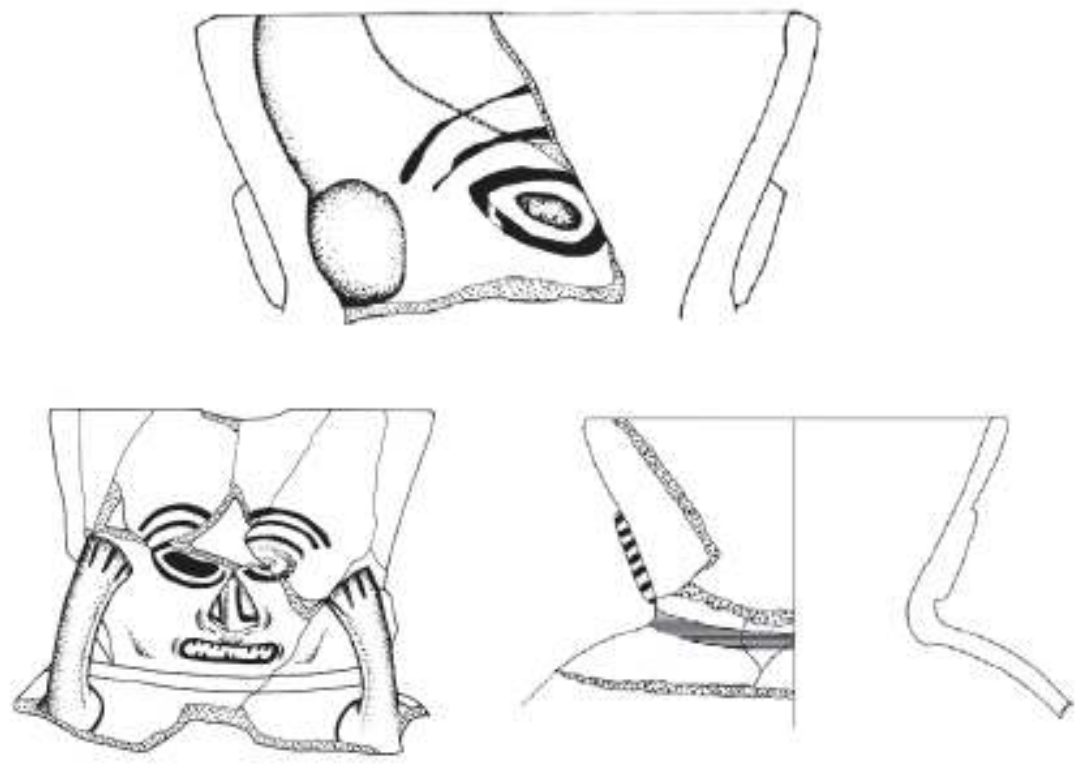

Fig. 7 - Fragmentos en estilo Pueblo Viejo: d. alfar $n^{\circ} 9$

d)
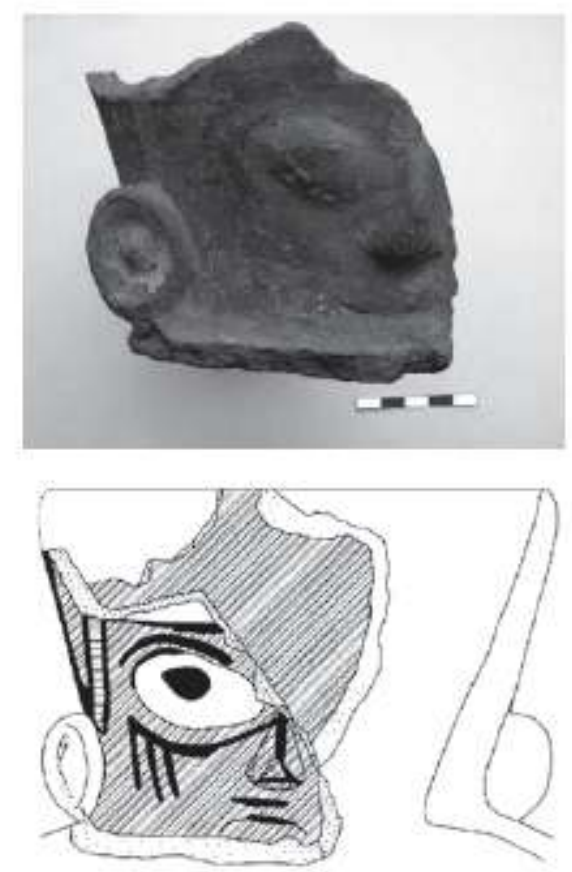

Mediana recurrencia posee en nuestra muestra el alfar $n^{\circ} 4$, con dos pastas diferentes $D$ y $\mathrm{H}$, que se relacionan con el mismo repertorio de formas. Hemos encontrado algunas piezas enteras o fragmentos grandes (vg. asa puente calada de botella doble con el característico gollete) que comparten estas características de pasta y pueden asignarse sin duda al estilo Chimu Inca (Fig. 8). El alfar $\mathrm{n}^{\circ} 4$ se caracteriza por engobes grises producto de la cocción reductora o reductora en enfriamiento. Las formas más frecuentes son los cuencos miniatura, botellas y cántaros. Strong \& Corbett (1943: fig. 11) denominaron a este tipo de cerámica "el estilo negro pulido inca asociado". 
Fig. 8 - Alfar $n^{\circ} 4$, cerámica en varios estilos, entre otros Inca (a) y Chimú-Inca (b)

a)
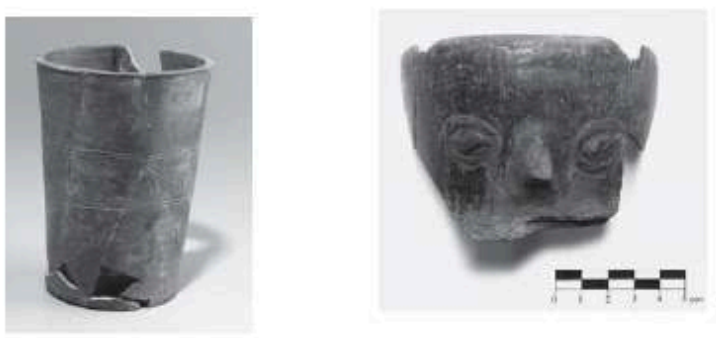

b)
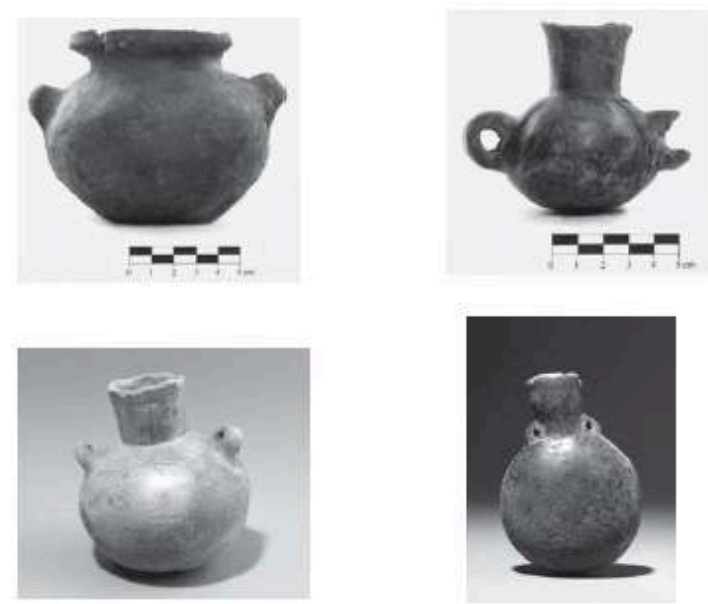

115 Similares niveles de popularidad tiene el alfar $n^{\circ} 6$ con dos ligeras variantes de pasta G-1 y G-2. Las vasijas más recurrentes son: cántaros, ollas, cuencos miniaturas, ollas con estampados y modelados-aplicados “ojo de papa". También se relaciona con formas Inca provincial como los aríbalos. Hay fragmentos pintados pre-cocción de color crema sobre pasta, crema sobre engobe rojo y negro sobre marrón. Los diseños son antropomorfos y geométricos. Algunas formas y decoraciones recuerdan lo que a veces recibe la denominación de Ychsma Tardío (Fig. 9). 
Fig. 9 - Cerámica Ychsma e Inca provincial, alfar $n^{\circ} 6$
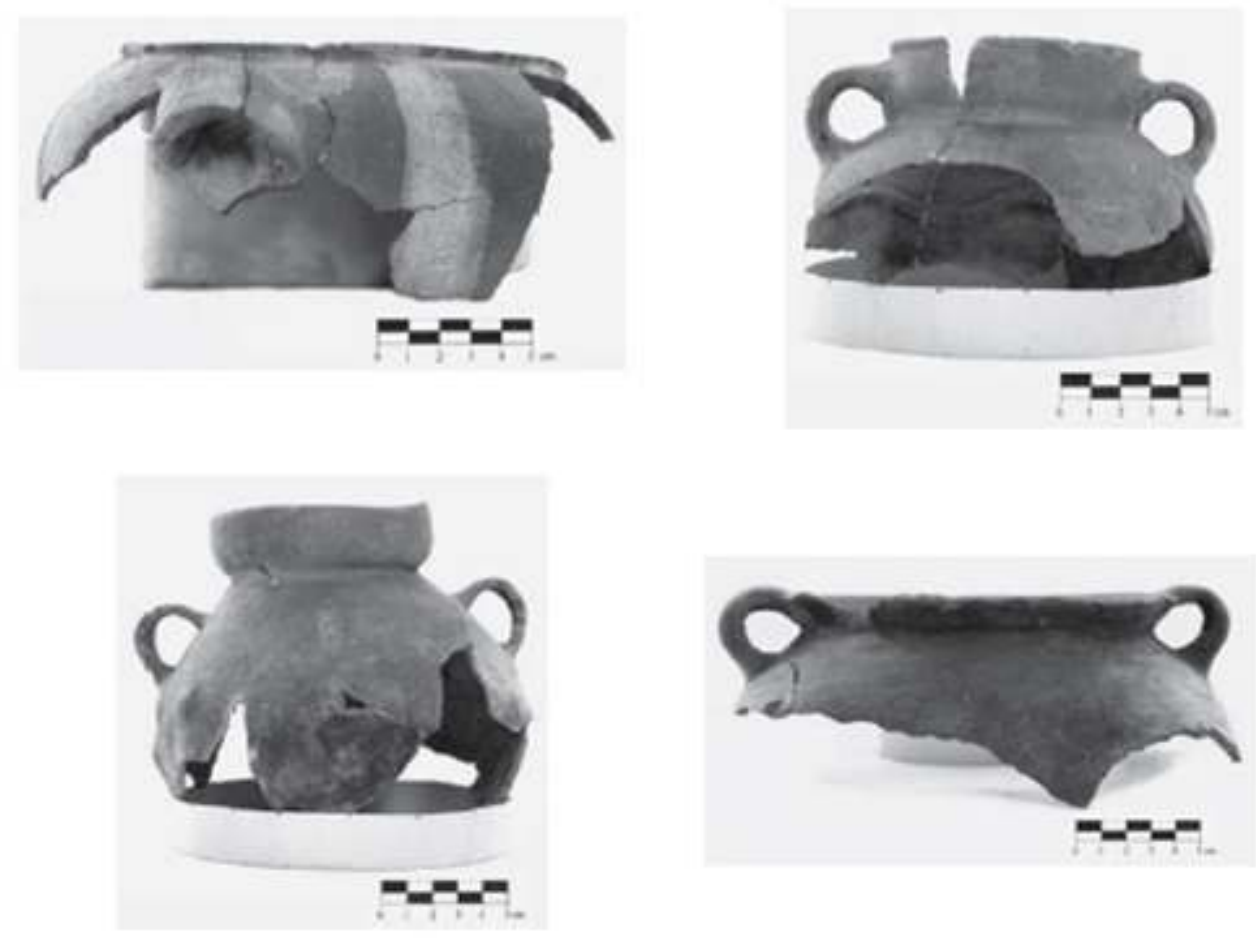

116 Muy poco representados son los alfares 7 (pasta I), 11 (pasta M), 12 (pasta N), y 13 (pasta O). Se trata de fragmentos de vasijas ceremoniales de cocción oxidante, con superficies bruñidas y pastas de color naranja con engobes y acabados finos (ver Makowski, 2003: fig $10 \mathrm{~B}$ y $10 \mathrm{C})$.

117 El ultimo grupo de tres alfares poco representados por los $\mathrm{n}^{\circ} 3,15$ y 16 (ver cuadro 2), caracterizados cada uno por un tipo de pasta de color anaranjado, C, Q, R, comprende fragmentos de vasijas grandes de almacenamiento, las que presentan engobe rojo y crema. Su acabado es burdo y la decoración escasa, en la mayoría de los casos.

\section{Algunas conclusiones}

118 El análisis expuesto reveló que la cerámica utilitaria de formas chicas y medianas de mayor uso, cántaros, ollas, cuencos y platos, se relaciona con la tradición serrana de alfarería de pasta marrón Huarochirí, lo que concuerda bien con el diseño arquitectónico y con las técnicas de construcción. La fragmentería de este tipo constituye no más de $40 \%$ de la muestra. El resto se reparte entre las vasijas muy variadas desde el punto de vista de la tecnología, el estilo y la probable procedencia. La población de Pueblo Viejo-Pucará tuvo amplio acceso a los recipientes cerámicos en estilos conocidos en la literatura como Ychsma o Ichma y Puerto Viejo. Tal como lo hemos sospechado, los talleres que produjeron alfarería en los estilos costeños y serranos, tradicionalmente atribuidas al Periodo Intermedio Tardío seguían plenamente activos durante el Horizonte Tardío. Los fragmentos y las vasijas en estos estilos están directamente asociados en pisos sellados y contextos de ofrendas con otras en estilo inca local. Se trata de aríbalos y algunas ollas con diseños geométricos (líneas, triángulos, puntos) de colores negro, marrón, crema, blanco, anaranjado y rojo. Se ha 
registrado algunos fragmentos y dos piezas enteras polícromas con diseños de helechos, inspirados en Cuzco polícromo A (Rowe, 1944).

Las decoraciones aplicadas con el motivo de serpiente, según Bazán (1992: 27-32) se derivarían del repertorio de Horizonte Medio, y caracterizarían al estilo "Ychsma fitomorfo" (ver Fig. 10). Sin embargo, parecen tener un claro origen cusqueño y las ollas de Pueblo Viejo-Pucará imitan claramente las ollas de estilo inca encontradas en Cuzco y sus alrededores (Pardo, 1939: Láminas 3 y 5; Bauer, 1992:104; Farfán, 2000: Figs. 9 y11). En todo caso, los antecedentes de este tipo de motivos decorativos que se conoce en el valle del Lurín desde las primeras fases del Periodo Intermedio Temprano no parecen guardar ninguna relación directa con los diseños del Horizonte Tardío $\left({ }^{10}\right)$.

Fig. 10 - Ollas con aplicaciones de serpientes, imitación Inca
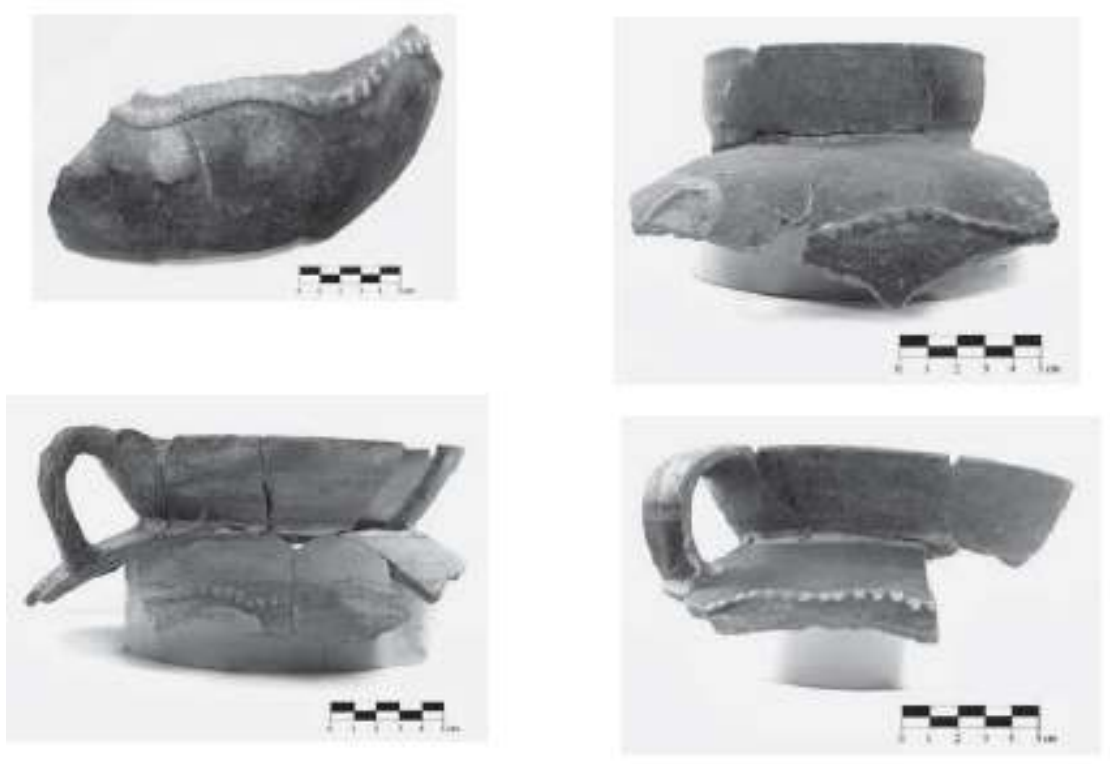

La conquista inca y la presencia de la administración imperial no tuvieron por ende como consecuencia el ocaso o la decadencia de estilos locales. Todo lo contrario. Artesanos de la Costa Central tuvieron la oportunidad de convivir con los especialistas foráneos desplazados. Su producción solo en parte quedó afectada por la aculturación en un medio pluricultural, y por la impronta que dejó el discurso con el estilo oficial, imperial. En muchos casos se ha producido la afirmación de su identidad tecnológica y estilística frente a los advenedizos que no fue incompatible con algunos préstamos. El contacto y el discurso entre tradiciones ha favorecido sin duda la mejora del nivel tecnológico de talleres locales. Uno de los varios ejemplos posibles de este fenómeno está en los variantes Inca del estilo Pueblo Viejo. Nos referimos a los cántaros caracuello que se caracterizan por la representación de las orejeras modeladas y la representación de "ojos llorosos".

121 Consideramos también posible que el incremento de la presencia de diseños y formas serranas locales en la producción alfarera costeña al sur del Chillón es otro de los efectos de la conquista inca. Los diseños con círculos estampados o impresiones de cañas caracterizan la decoración de ciertas vasijas del alfar 10 (pasta L) de Pueblo Viejo, que se relacionan con las formas costeñas locales Ychsma. Como técnica decorativa se encuentran en diferentes períodos y área de los Andes Centrales. Para la Costa Central Isla sugiere que tienen su origen en los estilos epigonales del Horizonte Medio (1995: 
88). Los paralelos más cercanos para nuestros fragmentos provienen sin embargo de Chancay (Cornejo, 1992: 327-328; Krzanowski, 1991: 239), de estilo Lauri impreso. Krzanowski, observa de manera acertada que esta tradición decorativa tiene su origen en la sierra y que se difunde hacia la costa durante el Intermedio Tardío y Horizonte Tardío creando una especie de "horizonte regional de círculos estampados" (Krzanowski, 1991: 235- 237). Eeckhout (1999: 48) cita casos que demuestran la distribución de esta técnica decorativa en el valle del Mantaro, la costa nor-central, los valles del Huaura, Chillón, ocasionalmente Rímac y Lurín. Sin embargo no necesariamente se trata de la difusión a partir de uno o dos focos.

Cuadro 3 - Pastas, alfares y acabados en las muestras de Pueblo Viejo y Pachacamac

\begin{tabular}{|c|c|c|c|c|}
\hline \multicolumn{2}{|c|}{$\begin{array}{l}\text { Cerámica de } \\
\text { Pueblo Viejo }\end{array}$} & \multirow{2}{*}{$\begin{array}{c}\text { Cerámica de Pueblo } \\
\text { Viejo: variedades según } \\
\text { los criterios de cocción } \\
\text { y acabado }\end{array}$} & \multirow{2}{*}{$\begin{array}{c}\text { Presencia de } \\
\text { alfares de } \\
\text { Pueblo Viejo } \\
\text { en el material } \\
\text { de Pachacamac, } \\
\text { (cortesía de } \\
\text { Daniel } \\
\text { Guerrero) } \\
\text { Alfar }\end{array}$} & \multirow{2}{*}{$\begin{array}{c}\text { La presencia } \\
\text { del estilo } \\
\text { inca en } \\
\text { la muestra } \\
\\
\text { Estilo }\end{array}$} \\
\hline Alfares & Pastas & & & \\
\hline Alfar 1 & A & Tipo anaranjado alisado & $x$ & Inca \\
\hline Alfar 2 & B & $\begin{array}{l}\text { Tipo anaranjado (pintura } \\
\text { crema, negro y rojo) }\end{array}$ & $x$ & \\
\hline Alfar 3 & C & $\begin{array}{l}\text { Tipo anaranjado tosco } \\
\text { (vasijas grandes) }\end{array}$ & $x$ & \\
\hline Alfar 4 & DyH & Tipo gris & $\mathrm{x}$ & Inca \\
\hline Alfar 5 & $\begin{array}{l}\text { E-1, E-2 } \\
\text { y F }\end{array}$ & Tipo marrón llano & $\mathrm{x}$ & \\
\hline Alfar 6 & G-1 y 2 & $\begin{array}{l}\text { Tipo anaranjado tosco } \\
\text { con engobe rojo }\end{array}$ & $\mathrm{x}$ & Inca \\
\hline Alfar 7 & I & Tipo anaranjado bruñido & $\mathbf{x}$ & Inca \\
\hline Alfar 8 & $\mathrm{~J}$ & Tipo anaranjado & $\mathrm{x}$ & \\
\hline Alfar 9 & $\mathrm{~K}$ & $\begin{array}{l}\text { Tipo anaranjado (pintura } \\
\text { crema, negro y rojo) }\end{array}$ & & Inca \\
\hline Alfar10 & L & Tipo anaranjado tosco & & \\
\hline Alfar 11 & M & Tipo anaranjado pulido & & \\
\hline Alfar 12 & $\mathrm{~N}$ & Tipo anaranjado brun̄ido & & Inca \\
\hline Alfar 13 & o & Tipo anaranjado & & \\
\hline Alfar 14 & $P$ & $\begin{array}{l}\text { Tipo anaranjado con } \\
\text { engobe rojo }\end{array}$ & & Inca \\
\hline Alfar 15 & Q & $\begin{array}{l}\text { Tipo anaranjado alisado } \\
\text { y posible engobe rojo }\end{array}$ & & \\
\hline Alfar 16 & $\mathrm{R}$ & $\begin{array}{l}\text { Tipo anaranjado alisado } \\
\text { y posible engobe crema }\end{array}$ & & \\
\hline
\end{tabular}

Los resultados de nuestros trabajos en Pueblo Viejo-Pucará, probable colonia militar que protegía los accesos a Pachacamac y aseguraba el control de valle bajo, confirman una vez más que las poblaciones privilegiadas y las elites de poder estuvieron favorecidas a una escala sin precedentes con el acceso a un abanico de materias primas exóticas (Owen, 2001), de productos "suntuarios", símbolos de poder y de parafernalia ritual (Morris, 1995) incluyendo artefactos concebidos a varios cientos de kilómetros de distancia (D'Altroy, 2000; Costin \& Earle, 1989) así como sus imitaciones. La intervención de la organización administrativa imperial no se limitaba sin embargo a estos aspectos relativamente bien conocidos y descritos en varias publicaciones. El número y la variedad de alfares y estilos registrados respectivamente en Pueblo Viejo y en la IIIra muralla de Pachacamac son similares. Varios de ellos están presentes en ambos sitios (véase el cuadro 3). De igual manera se pueden comparar el repertorio de objetos y materias primas exóticas o suntuarias. Notables coincidencias encontramos también con los resultados de las investigaciones de Eeckhout (1999: 34-76) en las que compara la cerámica de la Pirámide con rampa $n^{\circ} 3$ con los hallazgos en otras partes del valle del Lurín. De las 15 pastas descritas, 10 han estado en uso durante el Horizonte 
Tardío y 3 corresponderían a piezas importadas, respectivamente en estilos Chancay e Inca Imperial. Estas 15 pastas se relacionan con la totalidad de tipos tecnológicoestilísticos diferenciados por Eeckhout. Dado que el investigador ha puesto énfasis en los conjuntos arquitectónicos y asentamientos, los que han sido construidos y usados en el Periodo Intermedio Tardío, como la pirámide con rampa $n^{\circ} 3$ en Pachacamac, puede sorprender el hecho de que la totalidad de sus tipos guarda plena vigencia en el Horizonte Tardío (11). Varios tipos de pasta determinados por Eeckhout parecen guardar correspondencia con nuestros alfares, pero sería aventurado afirmarlo sin la comparación directa y sistemática de ambas muestras (véase la nota 10 y los cuadros 2 y 3). La incidencia en la muestra del valle del Lurín del tipo Lurín Marrón Alisado, correspondiente probablemente a nuestro alfar 5, con $20,6 \%$, comparado al $70,6 \%$ del tipo Lurín anaranjado llama la atención $\left({ }^{12}\right)$. Recordemos que en el material de Pueblo Viejo-Pucará el alfar 5 constituye el $40 \%$ de la totalidad de fragmentos analizados.

Estas evidencias sugieren que la variedad estilística y tecnológica de cerámica hallada en Pueblo Viejo no se debe a un trueque a escala local emprendido individualmente por cada una de las familias o por la comunidad. Resulta más bien probable que parte de estos bienes que llegaban al curaca del Pueblo Viejo formaban parte de tributos hechos a la administración imperial.

\section{BIBLIOGRAFÍA}

BAUER, B., 1992 - Avances en arqueología andina, 144p.; Cusco: Centro de Estudios Regionales Andinos "Bartolomé de las Casas". Colección Archivos de Historia Andina, 16. Traducción de Javier Flores.

BAZÁN DEL CAMPO, F., 1990 - Arqueología y Etnohistoria de los períodos prehispánicos tardíos de la costa central del Perú. Tesis para optar el título de licenciado en Arqueología; Lima: UNMSM.

BAZÁN DEL CAMPO, F., 1992 - Arqueología de Lima: Evaluación del término Huancho. Los estilos de cerámica de Lima a fines del horizonte Medio, 43p.; Lima: CREARTES.

BONAVIA B, D., 1959 - Cerámica de Puerto Viejo (Chilca). In: Actas del II congreso Nacional de Historia del Perú (época prehispánica): 137-168; Lima: Centro de estudios históricos y militares del Perú.

BUENO MENDOZA, A., 1982 - El antiguo valle de Pachacamac. Boletín de Lima, n 24 (4): 10-29; Lima.

BURGER, R., 1988 - Unity and heterogeneity within the Chavin Horizon. In: Peruvian Prehistory (Richard W. Keatinge, ed.): 99-144; New York: Cambridge University Press.

BURGER, R., 1993 - The Chavín Horizon: Stylistic Chimera or Socioeconomic Metamorphosis? In: Latin American Horizons (Don Stephen Rice, ed.): 41-82; Washington D.C.: Dumbarton Oaks. A Symposium at Dumbarton Oaks, October 11-12th, 1986. 
CHASE-DUNN, C. \& HALL, T. D., 1997 - Rise and Demise. Comparing World-Systems, New Perspectives in Sociology; Boulder, Colorado: Westview Press.

COCK, G. A. \& GOYCOCHEA DÍAZ, C. E., 2004 - Puruchuco y el cementerio inca de la Quebrada de Huaquerones: Puruchuco y la Sociedad de Lima. In: Un Homenaje a Arturo Jiménez Borja (Luis F. Villacorta, ed.): 179-197; Lima: CONCYTEC.

CONKEY, M. \& HASTDORF, C. (eds.), 1990 - The use of style in archaeology. New Directions in archaeology; Cambridge, Nueva York, Oakleigh: Cambridge University Press.

COOK, A., 1994 - Wari y Tiwanaku: Entre el estilo y la imagen, 344p.; Lima: Pontificia Universidad Católica del Perú.

CORNEJO, M., 1992 - Cronología y costumbres sepulcrales en Lauri, valle de Chancay. In: Estudios de Arqueología Peruana (D. Bonavia, ed.): 311-354; Lima: FOMCIENCIAS.

COSTIN, C.L. \& EARLE, T., 1989 - Status distinction and Legitimation of Power as Reflected in Changing Patterns of Consumption in Late Prehispanic Peru. American Antiquity, 54(4): 691-714.

D'ALTROY, T., 1992 - Provincial Power in the Inka Empire, 272p.; Washington: Smithsonian Institute.

D'AlTROY, T., 2000 - Remaking the Social Landscape: Colonization in the Inka Empire; Santa Fe: School of American Research Conference, The Archaeology of Colonization, March 19-23, Ms.

D'ALTROY, T., LORANDI, A. M. \& WILLIAMS, V., 1992 - Producción y uso de cerámica en la economía política Inca. In: Tecnología y organización de la producción de cerámica pre-hispánica (Izumi Shmada, ed.): 395-441; Lima: PUCP.

DAVIS, W., 1990 - Style and history in art history. In: The use of style in archaeology. New Directions in archaeology (Conkey Margaret \& Christine Hastdorf, eds.): 18-43; Cambridge, Nueva York, Oakleigh: Cambridge University Press.

DeBOER, W., 1992 - Interaction, inmitation, and communication as expressed in style: the Ucayali experience. In: The uses of style in archaeology (Margart W. Conkey \& Christine A. Hastorf, eds.): 82-104; Cambridge: Cambridge University Press.

DeBOER, W. \& MOORE, J. A., 1982 - The measurment and meaning of stylistic diversity. Ñawpa Pacha, 20: 147-162; Berkeley: Institut of Andean Studies.

DIÁZ ARRIOLA, L. \& VALLEJO B., F., 2002 - Identificación de contextos Ichma en Armatambo. Arqueología y Sociedad, n 14: 47-75; Lima: Museo de Arqueología y Antropología UNMSM.

DIETLER, M. \& HERBICH, I., 1998 - Habitus, Techniques, Style: An Integrated Approach to the Social Understanding of Material Culture and Boundaries. In: The Archaeology of Social Boundaries (M. T. Stark, ed.): 232-263; Washington D. C.: Smithsonian Institution Press.

DOBRES, M. A., 2000 - Technology and social agency. Outlining a Practice Framework for Archaeology. Social Archaeology; Oxford, Malden, Ma.: Blackwell Publ.

DULANTO, J., 2001 - Dioses de Pachacamac: El Idolo y el Templo. In: Los Dioses del Antiguo Perú, vol. 2 (Krzysztof Makowski, comp.): 159-181; Lima: Banco de Crédito.

EARLE, T., 1987 - Specialization and the Production of Wealt: Hawaian Chiefdom and Inka Empire. In: Specialization, Exchange and Complex Societies (Elisabeth Brumfiel \& Timothy Earle, eds.): 64-75; Cambridge Mass: Cambridge University Press. New Directions in Archaeology.

EECKHOUT, P., 1998a - Le temple de Pachacamac sous l'Empire Inca. Journal de la Société des Américanistes, 84(1): 9-44; Paris. 
EECKHOUT, P., 1998b - Offrandes funéraires à Pachacamac et Pampa de las Flores. Exemple des relations entre les côtes nord et centrale du Pérou à l'époque pré-Inca. Baessler Archiv, Neue Folge, Band XLVI: 165-229.

EECKHOUT, P., 1999 - Pachacamac durant l'Intermédiaire Récent. Étude d'un site monumental préhispanique de la Côte Centrale du Pérou, 504p.; Oxford: BAR International Series.

EECKHOUT, P., 2000 - Investigaciones arqueológicas en la pirámide $\mathrm{N}^{\circ}$ III de Pachacamac, costa central de Perú. Estudios Latinoamericanos, n² 20: 19-40; Varsovia.

ENGEL, F.-A., 1966 - Geografía humana prehistórica y agricultura precolombina de la Quebrada de Chilca, T. 1, 110p.; Lima: Universidad Agraria.

FARFÁN, C., 1994 - Asentamientos Prehispánicos de la cuenca alta del Chillón. Gaceta Arqueológica Andina, vol. VI, n 24: 31-61; Lima.

FARFÁN, C., 2000 - La ocupación Inca en Cantamarca, Canta. Arqueología y Sociedad, 13: 173-198; Lima: Museo Nacional de Arqueología y Antropología UNMSM.

FELTHAM, J., 1983 - The Lurín valley, Peru: A. D. 1000- 1532. Un published Ph. D. Tesis; London University, Ms.

FRANCO JORDÁN, R., 1996 - El templo del Sol en Pachacamac, esplendor y poder; Lima.

FRANCO JORDÁN, R., 1998 - La pirámide con rampa No 2 de Pachacamac. Excavaciones y nuevas interpretaciones, 105p.; Trujillo.

GRAVES-BROWN, P., JONES, S. \& GAMBLE, C., 1996 - Cultural identity and archaeology. The construction of European Communities; Londres, Nueva York.

GUERRERO, D., 2004 - Cronología cerámica y patrones funerarios del valle de Rimac: una aproximación a los periodos tardíos. In: Puruchuco y la Sociedad de Lima: un Homenaje a Arturo Jiménez Borja (Luis F. Villacorta, ed.): 157-177; Lima: CONCYTEC.

HAYASHIDA, F., 1994 - Producción cerámica en el Imperio Inca: una visión global y nuevos datos. In: Tecnología y organización de la producción cerámica prehispánica en los Andes (I. Shimad, ed.): 443-474; Lima: Fondo Editorial de la PUCP.

HURT, T. D. \& RAKITA, G. F.M. (eds.), 2001 - Style and Function. Conceptual Sigues in Evolutionary Archaeology; Westport: Connecticut, London Bergin \& Garvey.

ISLA C., J., 1995 - Materiales recuperados por Max Uhle (1906-1907) en la Isla San Lorenzo, costa central del Perú. Gaceta Arqueológica Andina, nº 24: 73-91; Lima.

KAULICKE, P., 1998 - Max Uhle y el Perú antiguo, 363p.; Lima: Pontificia Universidad Católica del Perú.

KAULICKE, P., 2000 - La sombra de Pachacamac: Huari en la costa central. In: Huari y Tiwanaku: Modelos vs. Evidencias, Primera Parte (Peter Kaulicke, ed.): 313-358; Lima: PUCP. Boletín de Arqueología PUCP $n^{\circ} 4$.

KRZANOWSKI, A., 1991 - Sobre la cerámica Chancay de tipo Lauri impreso. In: Estudios sobre la cerámica Chancay, Perú (Andrzej Krzanowsk, ed.): 37- 56; Polonia: Universidad de Jaquelona.

LA LONE, D., E., 1994 - An Andean World-System: Production Transformations under the Inka Empire. In: The Economic Anthropology of the State (E. Brumfiel, ed.): 17-41; Lanham: University Press of America. Society for Economic Anthropology Monograph 11.

LAVALLÉE, D., 1965-1966 - Una colección de cerámica de Pachacamac. Revista del Museo Nacional, Tomo XXXIV: 220-246; Lima. 
LORANDI, A. M., 1988 - Los Diaguitas y el Tawantinsuyu: Una hipótesos del conflicto. In: La frontera del Estado Inca (T. D. Dillehay \& Patricia J. Netherly, eds.): 235-259; Oxford: British Archaeological Reports, International Series, $n^{\circ} 422$. Actas del $45^{\circ}$ Congreso Internacional de Americanistas, Bogotá, Colombia, 1985.

LORANDI, A. M., 1991 - Evidencias en torno a los mitmaqkuna incaicos en el N.O. Argentino, Anthropológica, 8: 213-236; Lima: Pontificia Universidad Católica del Perú.

LYNN BRAY, T., 2003 - Los efectos del imperialismo incaico en la frontera norte. Una investigación arqueológica en la sierra septentrional del Ecuador; Quito: Abya Yala- Marka-Instituto de Historia y Antropología Andinas.

MAKOWSKI, K. (comp.), 2000-2001 - Los Dioses del Antiguo Perú, vol I y II; Lima: Banco de Crédito, MAKOWSKI, K., 2003 - Arquitectura, estilo e identidad en el Horizonte Tardío: el sitio Pueblo Viejo-Pucara, valle del Lurín. Boletín de Arqueología PUCP, nº 6, 2002: 137-170; Lima: Pontificia Universidad Católica del Perú.

MAKOWSKI, K., 2004 - Primeras Civilizaciones. In: Enciclopedia Temática del Perú, vol. IX; Lima: Ediciones El Comercio.

MALPASS, M.A., 1993 - Variability in the Inca State. In: Provincial Inca. Archaeological and Ethnohistorical Assesment of the Impact of the Inca State (M.A. Malpass, ed.): 234-244; Iowa City: University of Iowa Press.

MOGROVEJO J., 1999 - Cajamarquilla y el fin de la cultura Lima. Boletín del Instituto Riva-Agüero (BIRA), 26: 227-243.

MORRIS, C., 1994 - Symbols to Power: Style and Media in the Inka State. In: Style, Society and Person: Archaeological and Ethnological Perspectives (Ch. Carr \& J. E. Neitzel, eds.): 419-433; Nueva York: Plenum Press.

MORRIS, C., 1998 - Inka Strategies of Incorporation and Governance. In: Archaic States (G. M. Feinman \& J. Marcus): 293-309; Santa Fe: School of American Research Press.

OWEN, B., 2001 - The Economy of Metal and Shell Wealth Goods. In: Empire and Domestic Economy (T.N. D’Altroy \& Ch. A. Hastdorf, eds.): 265-295; Nueva York: Kluwer Academic/Plenum Press.

PARDO, L., 1939 - Clasificación de la cerámica Cuzqueña (Época Incaica). Revista del Instituto del Cuzco: 3-15; Cuzco.

PAREDES, P. \& RAMOS, J., 1994 - Excavaciones arqueológicas en el sector Las Palmas, Pachacamac. Boletín de Lima, Vol. XVI, N 9: 313-349; Lima.

PEREGRINE, P., 1991 - Prehistoric Chiefdoms on the American Midcontinent: A World- System Based on Prestige Goods. In: Core/Periphery Relations in Precapitalist Worlds (Christopher ChaseDunn \& Thomas D. Hall, eds.): 193-211; Boulder-San Francisco-Oxford: Westview Press.

ROSTWOROWSKI, DE DIEZ CANSECO, M., 1972 - Breve ensayo sobre el Señorío de Ichma o Ychima. Arqueología PUC: Boletín del Seminario de Arqueología, 13: 37-51; Lima.

ROSTWOROWSKI, DE DIEZ CANSECO, M., 1978 - Señoríos Indígenas de Lima y Canta, 280p.; Lima: Instituto de Estudios Peruanos,

ROWE, J. H., 1944 - An introduction to the archaeology of Cuzco. Papers of the Peabody Museum of American Archaeology and Ethnology, vol. 27, $\mathbf{n}^{\circ} 2$; Cambridga, Ma.: Harvard Univesity.

SALOMON, F., 1980 - Los señoríos étnicos de Quito en la época de los Incas, 370p.; Otavalo: Instituto Otavaleño de Antropología. 
SALOMON, F., 1986 - Native lords of Quito in the age of the Incas. The Political Economy of North Andean Chiefdoms, 274p.; Cambridge: Cambridge University Press.

SALOMON, F., 1987 - A North Andean Status Trader Complex under Inka Rule. Ethnohistory, 34(1): 63-77.

SAUERLÄNDER, W., 1983 - From stilus to style: reflections on the fate and a notion. Art History, 6: 253-270.

SEGURA, R., 2001 - Rito y economía en Cajamarquilla. Investigaciones arqueológicas en el Conjunto arrquitectónico Julio C. Tello, 203p.; Lima: Pontificia Universidad Católica del Perú.

SHIMADA, I., 1991 - Pachacamac Archaeology. Retrospect and Prospect. In: Pachacamac. A Reprint of the 1903 Edition by Max Uhle, lxviiip.; Philadelphia: University of Pennsylvania. The University Museum of Archaeology and Anthropology.

SILLAR, B. \& DEAN, E., 2002 - Identidad étnica bajo el dominio Inka: una evaluación arqueológica y etnohistórica de las repercusiones del estado Inka en el grupo étnico Canas. In: Identidad y transformación en el Tahuantinsuyu y en los Andes coloniales, perspectivas arqueológicas y etnohistóricas. Primera parte: 205-264; Lima: PUCP. Boletín de Arqueología PUCP n 6.

STRONG, W. \& CORBETT, M., 1943 - A Ceramic Sequence at Pachacamac. In: Archeological Studies in Peru, 1941-1942 (William D. Strong, Gordon R. Willey \& John M. Corbett, eds.): 27-122; New York: Colombia University Press. Columbia University Studies in Archeology and Ethnology, vol. I.

VEGA CENTENO A., P. M., 2004 - Eliminación de desechos y formación de montículos de basura en el sitio de Pueblo Viejo-Pucará (Valle del Lurín ), Ms; Cusco: UNSAAC.

WALLERSTEIN, I., 1973 - The Modern World-System. Vols 1. Capitalist Agriculture and the Origins of the European World-Economy in the Sexteenth Century; New York: Academic Press.

WILKINSON, D., 1991 - Core, peripheries, and Civilizations. In: Core/Periphery Relations in Precapitalist Worlds (Christopher Chase-Dunn \& Thomas D. Hall, eds.):113-166; Boulder-San Francisco-Oxford: Westview Press.

\section{NOTAS}

1. Esta manera de entender el estilo, libre de ideas preconcebidas acerca de la relación necesaria entre la historia de formas, diseños y acabados y las entidades étnicas o las estadías de desarrollo caracteriza, es menester recordarlo, a la obra de John Howland Rowe, así como de varios de sus colaboradores.

2. Compárese a título de ejemplo las siguientes clasificaciones realizadas sobre el material de periodos tardíos proveniente de Pachacamac:

Las Palmas (Paredes y Ramos, 1994)Pirámide con rampa $n^{\circ} 2$ (Franco, 1998)Pachacamac y otros sitios del valle del Lurín (Eeckhout, 1999)Las Palmas llano

Las Palmas crema restregado

Las Palmas negro sobre crema

Las Palmas punteado en zonas

Las Palmas negro pulido

Las Palmas marrón Tosco

Las Palmas engobe rojo

Las Palmas guinda

Las Palmas naranja pulido

Las Palmas marrón micáceo 
Las Palmas gris- Ychsma tipo inciso punzonado

- Ychsma tipo rojizo bruñido y sin bruñir

- Ychsma tipo negro bruñido

- Ychsma tipo marrón oscuro/amarillo pálido

- Ychsma tipo marrón oscuro/ amarillo pálido asociado a lo Inca

- Inca asociado, compuesto por: a. - tipo amarillo pálido o blanco sobre engobe rojo

c. - tipo negro bruñido o pulidoTipo Lurín anaranjado

Tipo Lurín engobe rojo

En la clasificación de Eeckhout (1999: 34-76) el tipo de la cocción, el acabado y la pasta constituyen los criterios rectores en la clasificación estilística. Franco (1998: 44-62) prefiere dar mayor peso al acabado mientras que Paredes y Ramos a la técnica de decoración. La terminología empleada por los tres sugiere diferentes expectativas de los autores en cuanto a la representatividad de su material. Franco con el término Ichma sugiere que existe una formada tradición local, Ychsma, con una distribución espacial coincidente con la de fronteras políticas del señorío del mismo nombre. Eeckhout, más prudente, piensa en un conjunto de estilos imperantes en el valle, "estilos Lurín”, opuestos a estilos foráneos. Paredes y Ramos indican con los términos usados que su objetivo se limitaba a describir la variabilidad de la cerámica hallada localmente, en la periferia de Pachacamac.

3. "... a highly conditioned and ambivalent hermeneutical "construct" worked out at a distinct moment in social and intellectual history" (traducción K. Makowski).

4. Véase por ejemplo la defensa de esta postura desde las posiciones del neo-evolucionismo darviniano. no sin introducir el imperativo de la reconstrucción de cadenas operativas (en Hurt \& Rakita eds., 2001).

5. "En un grupo plenamente politético de artefactos, (1) cada artefacto posee un (amplio) número de atributos del grupo (clase); (2) cada atributo caracteriza a un (amplio) número de artefactos que conforman el grupo (la clase); cada artefacto que conforma el grupo (la clase) posee más de un atributo diagnóstico" (Davis, 1990:19; traducción K. Makowski).

6. Se encuentra entre las coordenadas UTM 18304211 E, 8650496 N. Durante los 5 años de excavaciones en área que abarcaron $3400 \mathrm{~m}^{2}$, se ha podido comprobar que todos sus componentes fueron construidos sobre el nivel esteril durante el Horizonte Tardío.

7. El material cerámico del Sector III fue comparado sistemáticamente con otros sectores y con la cerámica proveniente de las excavaciones de Daniel Guerrero y Hernán Carrillo en la portada de la IIIra muralla de Pachacamac.

8. El subrayado indica la presencia de cerámica inca local.

9. La existencia de todas las formas Ychsma Medio ilustradas en nuestro material puede tener dos explicaciones. Por un lado no está por excluir que se trata de tipos de cerámica que se seguían produciendo sin modificaciones formales o tecnológicas durante el Horizonte Tardío. Por otro lado, Daniel Guerrero (com. personal) quién ha realizado sus excavaciones en Armatambo a pocos metros de distancia, afirma que el nivel de entierros Ychsma Medio pertenece en realidad al conjunto estratigráfico del Horizonte Tardío. De ser fundada esta afirmación los entierros dichos Ychsma Medio corresponderían a población local de nivel bajo, cuyos ajuares carecen de componentes de cerámica decorada diagnóstica para el Horizonte Tardío.

10. Véase también la discusión en Eeckhout (1999: 58) con otros casos registrados en supuestos contextos del Intermedio Tardío y Horizonte Tardío.

11. Hemos resumido estos resultados en la siguiente tabla:

Pasta A, tipo Lurín decoración: marrón/crema, negro/cremaInca-Lurín* Anaranjadocrema/rojo, negro/rojo, bandas negras, círculos impresos, punteado en zonas

Pasta B, tipo Lurín Marróndecoración: serpientes aplicadas, círculos impresosInca-LurínPasta C, tipo Lurín Naranjadecoración: marrón/crema, negro/crema, crema/rojo, negro/rojo, círculos impresos, punteado en zonasInca-Lurín Pasta D, tipo Luríndecoración: bandas cremas, bandas 
negras, Inca-LurínEngobe Rojocrema/rojo, negro y crema/rojo, círculos impresos, punteado en zonas

Pasta E, tipo Luríndecoración: eventualmente incisa o modeladaInca-LurínNegro Pulido

Pasta F, tipo Luríndecoración: marrón/crema, negro/crema,Inca-LurínAnaranjadocírculos impresos, bandas negras, punteado en zonas Pasta G, tipo Luríndecoración: marrón/crema, negro/crema,Inca-LurínAnaranjadocrema/rojo, negro/rojo, bandas negras, círculos impresos, punteado en zonas

Pasta H, tipo Luríndecoración: eventualmente incisa o modelada

Negro Pulido

Pasta I, tipo Luríndecoración: marrón/crema, negro/crema,Inca-LurínAnaranjadocrema/rojo, negro/rojo, bandas negras, círculos impresos

Pasta J, tipo Luríndecoración: crema/rojo, negro/rojoInca-LurínAnaranjado

Pasta K, tipo Luríndecoración: punteado en zonasInca-LurínAnaranjado

Pasta L, tipo Lurín

Anaranjado

Pasta M, cerámica

importada Chancay

Pasta N, cerámica

importada Chancay

Pasta O, cerámica importada

Inca (sólo de Chaymayanca y Avillay)

Inca

* la anotación "Inca-Lurín" indica la presencia de fragmentos con elementos diagnósticos del Horizonte Tardío.

12. Según Eeckhout (1999: 58) este tipo corresponde a "Browne Ware " de Feltham (1983: 830-867)," “Marrón" de Lurín y Rimac de Bazán (1990: 115), entre otros y se relacionaría con una tradición serrana.

\section{RESÚMENES}

La imagen establecida sobre el Horizonte Tardío se ha vuelto mucho más compleja gracias a las excavaciones a gran escala emprendidas en los últimos años. Una variedad notable de estilos y alfares de cerámica fue descubierta no solo dentro del área del mismo yacimiento arqueológico sino incluso dentro del mismo contexto primario, tanto en Pueblo Viejo-Pucará, el asentamiento urbano de mitimaes abandonado inmediatamente después de la conquista española, probable asentamiento principal de los Caringa de Huarochirí, localizado a $15 \mathrm{~km}$ de Pachacamac en el valle del Lurín , como en otros sitios del mismo periodo. Las identidades de productores, de los encargados de distribución y de los usuarios raramente son coincidentes porque el imperio ha creado las condiciones de mini-sistema-mundo y realizaba además la bien conocida política de desplazamientos forzados de artesanos y de poblaciones enteras, especializadas en ciertas áreas de producción. La procedencia hipotética de los constructores de Pueblo Viejo-Pucará de la sierra de Huarochirí se sustenta en la organización espacial del asentamiento, en la mampostería, en el diseño arquitectónico, en los comportamientos funerarios registrados, y en las fuentes escritas del siglo XVI. El análisis convencional macroscópico y microscópico de cerámica en una muestra de 3456 fragmentos diagnósticos seleccionados entre 41871 tiestos registrados ha permitido 
definir 16 alfares y varios estilos: "Ychsma" local del valle bajo, la cerámica marrón del valle alto, "Puerto Nuevo" de la costa, estilo influenciado por la Costa Norte, incluyendo el "Chimú-Inca", el "Inca provincial". El caso de Pueblo Viejo-Pucará demuestra una vez más que en el contexto de periodos tardíos, la arquitectura y los comportamientos funerarios constituyen mejores indicadores de la "identidad étnica" de los constructores y usuarios de un asentamiento que el estilo de cerámica. Las tradiciones cerámicas del Periodo Intermedio Tardío se han mantenido vigentes durante el Horizonte Tardío. No obstante, el desplazamiento de mitimaes, incluyendo a los alfareros especializados, hacia la Costa Central ha tenido algunos efectos inmediatos: han surgido nuevos estilos y nuevos diseños formales y decorativos.

Grâce aux fouilles intensives menées ces dernières années notre perception de l'Horizon Récent est beaucoup plus raffinée qu'auparavant. Un grand nombre de traditions technologiques potières et de styles ont été enregistrés pendant les fouilles de Pueblo Viejo-Pucará, une ville fondée par les mitimaes dans la vallée de Lurín, a $15 \mathrm{~km}$ de Pachacamac, et abandonnée juste après la conquête espagnole. Il s'agit probablement de la capitale de la communauté des Caringa de Huarochirí. On observe la même situation sur d'autres sites archéologiques fouillés sur la Côte Centrale. L'identité des producteurs, de ceux qui s'étaient chargés de la distribution, et de ceux qui utilisaient les objets fabriqués, coincident rarement, puisque l'Empire Inca avait créé les conditions d'un " mini-système monde ». Il avait également mis en place la politique bien connue des déplacements forcés des artisans et des populations entières, spécialisées dans certains types de production. On déduit la provenance de ceux qui ont construit Pueblo Viejo-Pucará, village des hautes terres de Huarochirí, à partir de l'organisation spatiale de la ville, des traits caractéristiques de l'architecture, de la maçonnerie même, des coutumes funéraires et des sources écrites du XVIème siècle. L'analyse conventionnelle de céramique, macroscopique et microscopique d'un échantillon de 3456 fragments sélectionnés parmi 41871 tessons recueillis, a permis de définir 16 traditions technologiques potières co-existantes et plusieurs styles: l'« Ychsma » local de la basse vallée, la céramique brune de la haute vallée, « Puerto Viejo » de la côte, style influencé par les traditions de la côte nord, y compris «Chimú-Inca », Inca des provinces. Le cas de Pueblo Viejo-Pucará démontre une fois de plus, pour les périodes récentes, que l'architecture et les coutumes funéraires sont meilleurs indicateurs de l'identité " ethnique » des constructeurs et des habitants que le style de la céramique. Les traditions potières de la Période Intermédiaire Récent ont survécu pleinement à la conquête inca. Néanmoins le déplacement des mitimaes, y compris quelques groupes d'artisans, vers la côte centrale a eu des conséquences immédiates : des nouveaux motifs et des nouveaux styles apparurent.

The picture that is currently being developed for the Late Horizon is far more complex now, thanks to the intensive field research recently undertaken in the last years. In Pueblo ViejoPucara, a mitimaes settlement abandoned in just after the Spanish conquest, perhaps the chief town of the Caringa from Huarochiri moiety (12 ha and about 570 family units), which lies $15 \mathrm{~km}$ from Pachacamac in the Lurin Valley, like in other sites from the same period, remarkable variety of ceramic styles and wares were recorded not just within the same area or site, but even within the same primary context. The identities of the producers, distributors, and the builders of domestic and public spaces rarely coincide because the empire gave rise to miniature world system conditions and used the well-known policy of forced relocation of artisans and whole populations specialised in certain areas of production. The conclusion regarding the highland provenance of the builders of Pueblo Viejo-Pucará is supported by the spatial organisation of the settlement, bonding, architectural design, burial rituals and many written sources from XVI s. The conventional macroscopic and microscopic analysis of the wares in the sample comprising 3456 diagnostic fragments chosen among 41871 sherds, enabled the definition of 16 different technological traditions of pottery making and many styles: local lower valley "Ychsma", brown upper valley ceramic, coastal "Puerto Viejo", north coastal influenced including Chimu Inca, 
provincial Inca. The case of Pueblo Viejo-Pucará once more evinces that in the context of late periods, architecture, funeral behaviour and not ceramics are the best indicators of the identity of the builders and the users. The Late Intermediate Period ceramic traditions lasted throughout the Late Horizon. However, the transfer of mitimaes -including some skilled potters- to the Central Coast had some immediate effects: new design and new styles appears.

\section{ÍNDICE}

Mots-clés: Inca, Horizon Récent, ethnicité, Ychsma (Ichma), style de céramique, Pachacamac, Huarochirí, mitimaes (Mitmaquna).

Palabras claves: Inca, Horizonte Tardío, etnicidad, Ychsma (Ichma), estilo de cerámica, Pachacamac, Huarochirí, mitimaes (Mitmaquna).

Keywords: Inka, Late Horizon, Ethnicity, Ychsma (Ichma), Pottery Style, Pachacamac, Huarochirí, Mitimaes (Mitmaquna).

\section{AUTORES}

\section{KRZYSZTOF MAKOWSKI}

Pontificia Universidad Católica del Perú, Departamento de Humanidades, Arqueología. E-mail: kmakows@pucp.edu.pe

\section{MILENA VEGA CENTENO A.}

Pontificia Universidad Católica del Perú. Proyecto PUCP - Cementos Lima “Lomas de Lurín”. Email: milenavegacenteno@hotmail.com 